\title{
TERMOBAROMETRIA DAS OCORRÊNCIAS ANFIBOLÍTICAS DE ERMIDA, COMPLEXO ITAPIRA (SP)
}

\author{
STELLA CRISTINA ALVES DE SOUZA ${ }^{1} \&$ MARCOS AURÉLIO FARIAS DE OLIVEIRA
}

\begin{abstract}
The Ermida Amphibolite Occourrences are a group of four lenses represented by labradorite-bytownite amphibolite, in migmatizated garnet-sillimanite gneiss of Itapira Complex, at Jundiai, São Paulo State. The parageneses plagioclase + hornblende + clinopyroxene + ilmenite + garnet and epidote + chlorite + actinolite (hornblende) + titanite + calcite + quartz indicate a metamorphic peak $\left(M_{1}\right)$ and retrometamorphism $\left(M_{2}\right)$, respectively, with clockwise P-T path. The first episode $\left(M_{1}\right)$ developed under colisional regime $\left(\mathrm{D}_{\mathrm{n}-1} / \mathrm{D}_{\mathrm{n}}\right)$, obliterating all relict features of the amphibolite protholites, converting them to granoblastic texture and generating $\mathrm{S} 1$ foliation, under temperature conditions between $700^{\circ}$ and $830^{\circ} \mathrm{C}$ and pressure between $6-7 \mathrm{kbar}, 22 \mathrm{~km}$ of depth, upper amphibolite facies. The retrogressive metamorfism $\left(M_{2}\right)$ is contemporaneous with $\left(D_{n+1} / D_{n+3}\right)$, it is incipient and it does not change the textures formed in M1. It was developed at the temperature between $450^{\circ}-550^{\circ} \mathrm{C}$ and $2-4 \mathrm{kbar}$ of pressure, $7 \mathrm{~km}$ of depth, in the greenschist to amphibolite facies transition. The petrographic characteristics exhibited by the amphibolites are similar to other ones dispersed in other localities of Itapira Complex, suggesting that the temperature and pressure indicated in this paper have reached in the whole unit.
\end{abstract}

Keywords: Itapira Complex, amphibolites, geothermobarometry, mineral chemical, metamorphism, amphibolite facies, greenschist facies

\begin{abstract}
Resumo As ocorrências anfibolíticas de Ermida são um conjunto de quatro lentes representadas por labradorita-bytownita anfibolitos, inseridos em granada-sillimanita gnaisses migmatizados do Complexo Itapira, no município de Jundiaí, no Estado de São Paulo. O desenvolvimento das paragêneses plagiocásio + hornblenda + clinopiroxênio + ilmenita + granada e epidoto + clorita + actinolita (hornblenda) + titanita + calcita + quartzo indicam, respectivamente, o pico metamórfico $\left(\mathrm{M}_{1}\right)$ e o retrometamorfismo $\left(M_{2}\right)$, em trajetória horária. O primeiro episódio $\left(M_{1}\right)$ desenvolveu-se sob regime colisional $\left(D_{n-1} / D_{n}\right)$, obliterando todas as feições reliquiares dos protólitos dos anfibolitos, convertendo-as em textura granoblástica e gerando a foliação $S_{1}$, sob condições de temperatura entre $700^{\circ}$ e $830^{\circ} \mathrm{C}$ e pressão entre $6-7 \mathrm{kbar}$, a $22 \mathrm{~km}$ de profundidade, facies anfibolito superior. $\mathrm{O}$ retrometamorfismo $\left(\mathrm{M}_{2}\right)$ é contemporâneo à fase $\left(\mathrm{D}_{\mathrm{n}+\mathrm{t}} / \mathrm{D}_{\mathrm{n}+3}\right)$, é incipiente, não desconfigura as texturas formadas em $\mathrm{M} 1$ e se desenvolveu sob condições entre $450^{\circ}-550^{\circ} \mathrm{C}$ de temperatura, entre $2-4 \mathrm{kbar}$ de pressão, a $7 \mathrm{~km}$ de profundidade, na transição entre a facies xisto verde e a facies anfibolito. As características petrográficas exibidas pelos anfibolitos, aqui analisados, são semelhantes a outros anfibolitos dispersos pelo Complexo Itapira em outras localidades, e sugerem que as condições de pressão temperatura aqui indicadas não são locais e podem ter sido alcançadas em toda unidade.
\end{abstract}

Palavras-chave: Complexo Itapira, anfibolitos, geotermobarometria, química mineral, metamorfismo, facies anfibolito, facies xisto verde.

INTRODUÇÃO Os orto-anfibolitos que constituem as ocorrências anfibolíticas de Ermida, bem como muitos outros encontrados pelo mundo, foram estudados, porque guardam a sua história evolutiva na sua composição química e modal e na sua textura e estrutura. Além disso, esta história se correlaciona com a evolução das unidades maiores às quais pertencem, neste caso, o Complexo Itapira. Esta história pode ser registrada, porque os minerais que compõem os anfibolitos são sensiveis às mudanças nas condições físicas e químicas do ambiente. Além disso, esses anfibolitos foram escolhidos para análise por haver a oportunidade destas rochas serem encontradas como núcleos resistentes à erosão e pedogênese, enquanto as rochas metassedimentares, sob as mesmas condições, são encontradas friáveis ou em estado avançado de alteração, dificultando as análises petrográficas e químicas. Outro fato levado em consideração é a sua homogeneidade, maior que a das rochas metassedimentares encaixantes, que normalmente exibem forte bandamento composicional.

Assim, o detalhamento das características minerais dos anfibolitos de Ermida foi obtido com a finalidade de conhecer a evolução metamórfica destas rochas e sua correlação com o metamorfismo de todo o Complexo Itapira. Para tanto, o passo inicial para a realização deste trabalho foi o mapeamento de detalhe de uma pequena porção do SW do município de Jundiaí, no limite entre as folhas Jundiaí e Indaiatuba, entre as coordenadas $47^{\circ} 00^{\prime} \mathrm{W}$ e $46^{\circ} 55^{\prime} \mathrm{W}$ e $23^{\circ} 10^{\prime} \mathrm{S}$ e $23^{\circ} 12^{\prime} \mathrm{S}$, em escala $1: 10000$.

Durante o mapeamento houve a coleta de 15 amostras de anfibolitos e todas foram laminadas, obtendo-se em seguida sua descrição petrográfica, cuja análise modal consta na tabela 1 . Destas 15 amostras, 3 foram selecionadas para análise de química mineral, obtendo-se 19 análises de anfibólios, 23 de plagioclásio, 4 de granada e 3 de piroxênio.

A análise petrográfica foi realizada utilizando-se o microscópio óptico OLYMPUS, BX40, no laboratório de microscopia do DPM/IGCE/UNESP. A análise química dos minerais foram obtidas por meio de microssonda eletrônica, JEOL, JX-8600 Super Probe, sob condições de $20 \eta \mathrm{A}$ de corrente da amostra, $20-30 \mathrm{keV}$ de potencial de aceleração, e abertura de feixe diferenciado, sendo de $5 \mu$ para anfibólio e piroxênio e $10 \mu$ para plagioclásio e granada. Este experimento foi realizado no laboratório do IG/USP. Os cálculos estruturais dos minerais analisados e diversos diagramas que se utilizam destes dados foram efetuados com auxílio do programa MINPET (Richard 1995). Os cálculos geotermobarométricos foram executados por meio do programa PTMAFIC (Soto \& Soto 1993), seguindo o método de Blundy \& Holland (1990).

GEOLOGIA REGIONAL Na região de Jundiaí e arredores são encontradas seqüências sedimentares representadas 


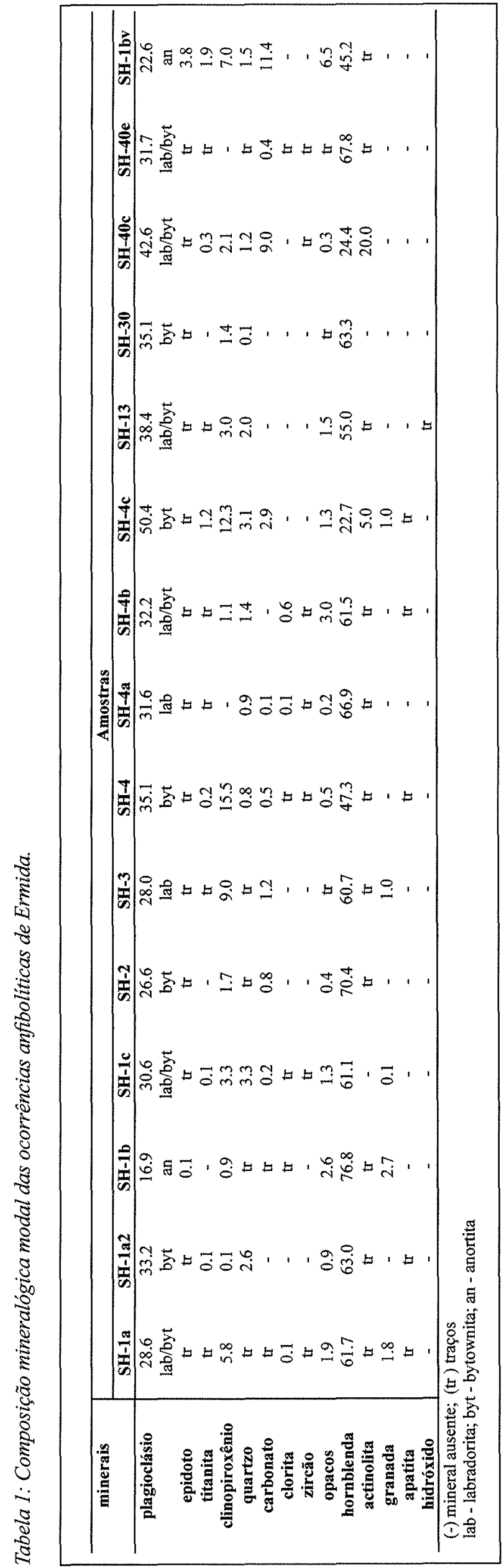

por depósitos coluvionares e aluvionares quaternários, diamictitos, conglomerados, arenitos e argilitos terciários e folhelhos, ritmitos, argilitos e siltitos paleozóicos, relacionados ao Grupo Itararé. Além destas, há intrusivas granitóides e unidades metassedimentares proterozóicas, estando presentes filitos do Grupo São Roque e gnaisses do Complexo Itapira (Neves 1999), como pode ser visto na figura 1 . Dentre estas unidades se destaca o Complexo Itapira, objeto deste trabalho, que se estende desta região para o Bloco Jundiaí, adentrando o estado de Minas Gerais. Este bloco é limitado por zonas de cisalhamento, sendo a ItuJundiuvira e Camanducaia a sul, Jacutinga a norte e a oeste pela Bacia do Paraná. O Complexo Itapira como um todo está representado principalmente por granada-sillimanita-biotita gnaisses, com graus variados de migmatização (Ebert 1971; Hasui et al. 1978; Wernick 1978). Estes gnaisses apresentam intercalações xistosas, anfibolíticas e cálcio-silicáticas, ocasionalmente granulíticas (Souza \& Silva 1992). Seqüências ofiolíticas são descritas no nordeste do Estado de São Paulo e sul de Minas Gerais (Lourenço et al. 1999). Ainda ocorrem outros tipos litológicos, como quartzitos e os gonditos, que chegam a formar grandes corpos, além de escarnitos, mármores, filitos, hornblenditos, metaultrabásicas.

A origem dos protólitos dos anfibolitos do Complexo Itapi$\mathrm{ra}$, indicada por numerosos dados químicos, está relacionada a arcos de ilhas ou cadeias meso-oceânicas (Oliveira et al. 1987; Souza 2001), ou sucessivos ambientes colisionais (Souza 1997) e que foram metamorfisados em facies anfibolito, especialmente identificado na presença de sillimanita das rochas metassedimentares encaixantes (Oliveira et al. 1987), ou provavelmente uma zona de transição para a facies granulito limitada entre 700 e $860^{\circ} \mathrm{C}$ de temperatura e 6 a 7 kbar de pressão (Souza 1997, Souza et al. 1996).

Os eventos tectono-termais sofridos pelo Complexo Itapira estão relacionados a colisões $\left(D_{n-1} / D_{n 1}\right)$ com transporte para $N W$, em facies anfibolito, seguido por evento transtensivo/transpressivo $\left(D_{n+1} / D_{n+3}\right)$, em facies xisto verde (Hackspacher 1994; Hackspacher et al. 1991, 1992a, b, c, 1996, 1999). As idades prováveis destes dois eventos são próximas a $2000 \mathrm{Ma}$ e $600 \mathrm{Ma}$, respectivamente (Cordani \& Bittencourt 1967; Hasui \& Hama 1972; Tassinari et al. 1988; Ebert et al. 1994).

OCORRÊNCIAS ANFIBOLÍTICAS DE ERMIDA Dentre as numerosas lentes e corpos intercalados nas rochas metassedimentares do Complexo Itapira, encontram-se as ocorrências anfibolíticas de Ermida, reconhecidas inicialmente por Hasui \& Hama (1972). Foram mapeadas inicialmente por Nogueira et al. (1985) e pouco foi modificado nos trabalhos posteriores (Souza \& Oliveira 1998; Souza 2001). A diferença principal consiste no reconhecimento de uma lente a mais, observada no último trabalho, além do detalhamento das características petrográficas e da quantificação do grau metamórfico nesta região, utilizando modelos geotermobarométricos aplicado aos anfibolitos.

Assim, as ocorrências anfibolíticas de Ermida formam um conjunto de 4 lentes, de orientação NW-SE, concordante com a estruturação das rochas metassedimentares encaixantes (figura 2), que são constituídos principalmente por granada-sillimanita gnaisses pouco migmatizados (figura 3a) e transicionam para os quartzitos da Serra do Japi, a sul. Os contatos são abruptos e discordantes com os granitos e ortognaisses, a norte, e com os sedimentos terciários e aluviões dispersos (Nogueira et al. 1985).

$\mathrm{O}$ metamorfismo regional foi estimado entre $760^{\circ}$ e $780^{\circ} \mathrm{C}$, similar ao que ocorre na folha Cabreúva (Souza 1997, Souza \& Oliveira 1998). Entretanto, a geotermobarometria revelou que a temperatura deve ser maior neste ponto, atingindo $830^{\circ} \mathrm{C}$, com pressões entre 5 e $7 \mathrm{kbar}$, sob condições de soterramento de no mínimo 22km (Souza 2001). 


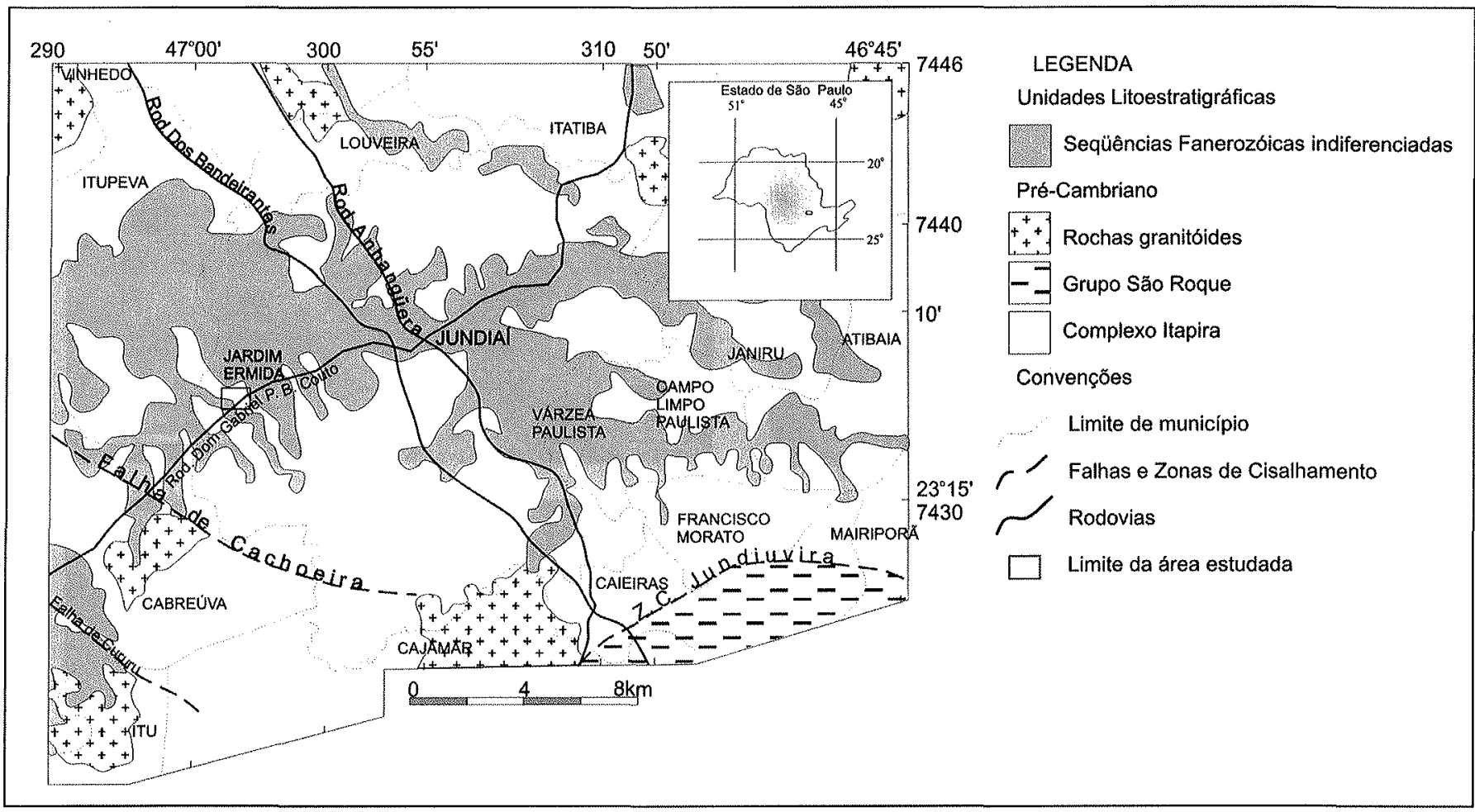

Figura 1 - Mapa geológico simplificado de Jundiai e arredores (Neves 1999, Neves et al 2003).

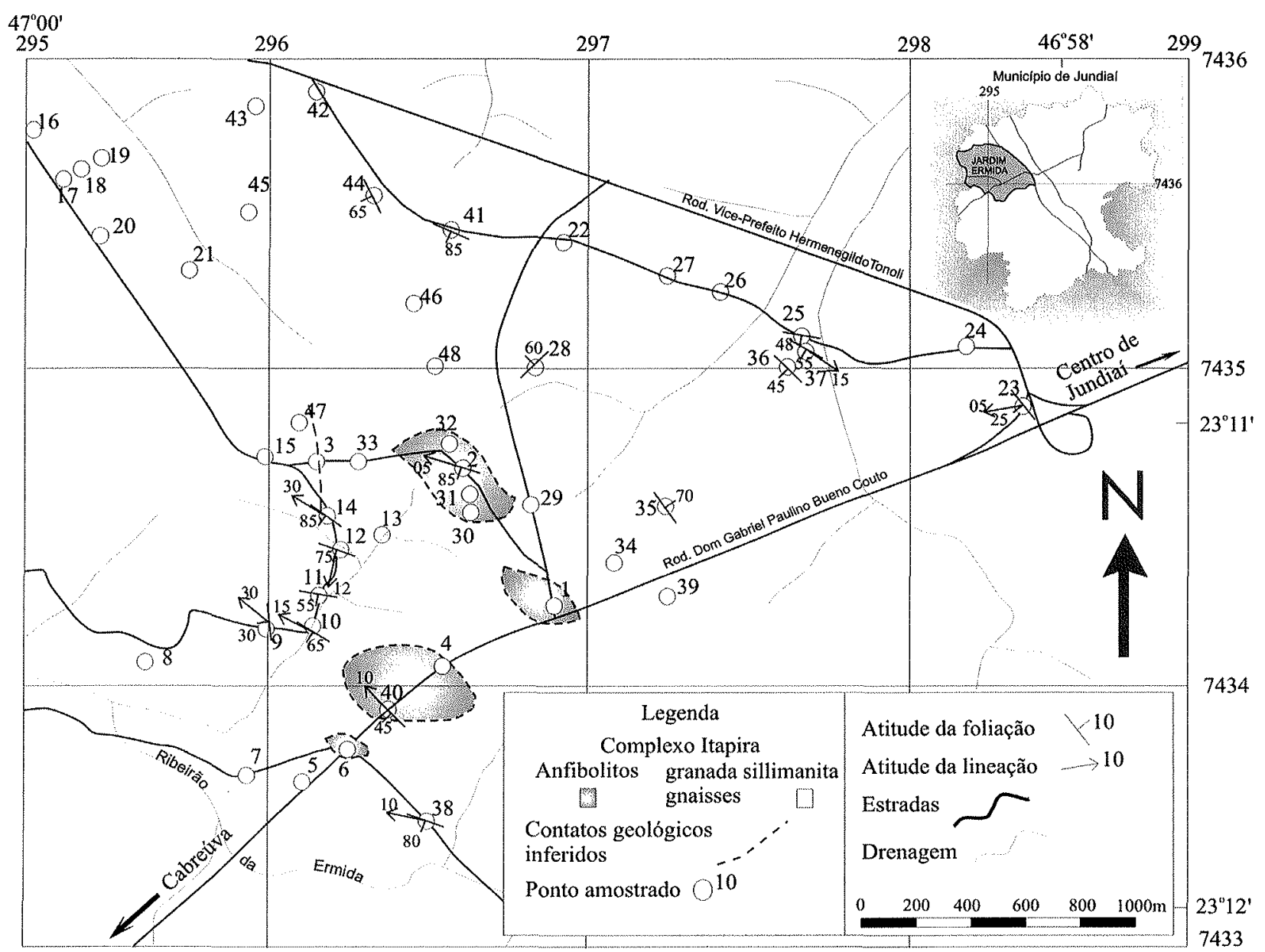

Figura 2 - Mapa geológico simplificado da região de Ermida e indicação de pontos amostrados (Souza 2001). 


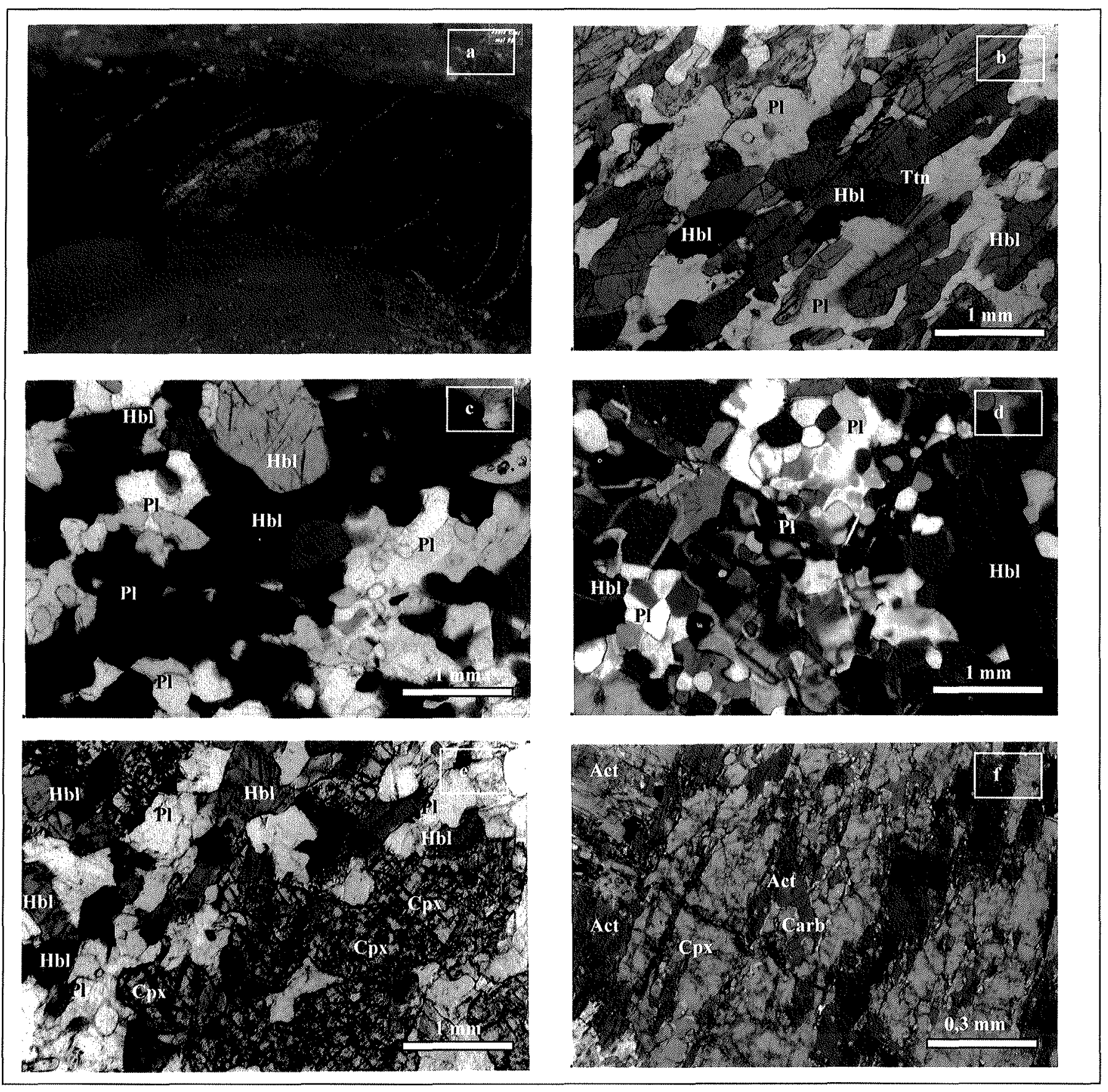

Figura 3-Características macroscópicas das encaixantes e texturas dos anfibolitos: (a) granada-sillimanita gnaisse migmatizado, ponto 36, figura 2. Notar venulações e bolsões leucograníticos paralelos à foliação; (b) amostra SH-4a, xistosidade em anfibolito marcada pela iso-orientação de cristais de hornblenda, (c)(d) amostra SH-1aa2, formas pseudo-hexagonais em cristais de hornblenda e plagioclásio, notar os contatos retos e as junções a aproximadamente $120^{\circ}$; (e) amostra SH-4, clinopiroxênio em contato com hornblenda e plagioclásio e formação inicial de epidoto entre as fraturas; (f) amostra SH-40, início da transformação retrometamórfica em clinopiroxênio, com recristalização de actinolita + carbonato na interface das clivagens e fraturas. Abreviações: Act (actinolita), Hbl (hornblenda), Pl (plagioclásio), Cpx (clinopiroxênio), Carb (carbonato) e Ttn (titanita).

Os anfibolitos da região de Atibaia (Souza \& Silva 1992), são semelhantes aos de Ermida, mas con hornblenda com tonalidades mais esverdeadas. Os anfibolitos da região de Cabreúva, descritos em Souza (1997), são mais heterogêneos, e apresentam hornblenda com tom marrom-avermelhado, muito mais intenso que as encontradas em Ermida, o que parece ser reflexo dos teores de $\mathrm{TiO}_{2}$ elevados, até 2,40\% (Souza 2001). Em todas as localidades a textura granoblástica, do tipo mosaico, está presente, evidenciando estágio de recristalização primária bem desenvolvida.
Petrografia As análises petrográficas das 15 amostras coletadas foram efetuadas com a finalidade de conhecer o conteúdo e $o$ arranjo dos minerais presentes nos anfibolitos, e, assim, associar estes aspectos a uma história tectono-metamórfica.

\section{TEXTURAS, ESTRUTURAS E COMPOSIÇÃO MINE-}

RAL O arranjo dos minerais visto no microscópio mostra que os anfibolitos apresentam somente uma foliação (S1), moderada a fortemente marcada, do tipo xistosidade (figura $3 \mathrm{~b}$ ) e raramente bandamento composicional. A foliação é dada por alinhamen- 
tos de cristais de hornblenda, com eixo "c" paralelo ou não à estrutura da rocha. A foliação é contínua, retilínea, ocasionalmente pode ser pouco sinuosa. No mapa, a orientação desta estrutura é maioria NW-SE, com alto ângulo de mergulho, ao redor de $70^{\circ}$, caindo para SW. A maioria das lineações observadas em campo são direcionais, sentido NW (figura 2). As microfraturas são representadas por três famílias de juntas, sendo uma dominante a aproximadamente $40^{\circ}$ de $\mathrm{S}_{1}$. As fraturas estão quase sempre vazias, mas epidoto, clorita, calcita e raros opacos podem estar preenchendo esses espaços, sendo que a calcita e a clorita se precipitam nos minerais félsicos e o epidoto e os opacos, nos minerais máficos. A família de juntas a $40^{\circ}$ da foliação se destaca por algumas características. O seu espaçamento, apesar de irregular, ocorre em uma média de cerca de $0,1 \mathrm{~mm}$. Esta família de juntas é um pouco mais retilínea e contínua que as demais, atravessando um mineral completamente e vários minerais, sem se desviar. Pode ainda arrastar lamelas ou promover o aparecimento de kink bands em plagioclásios.

A textura apresentada pelos anfibolitos é granoblástica decussada, de granulação na média de $1 \mathrm{~mm}$, ocorrendo numerosos cristais menores e maiores que este valor. A granada e o clinopiroxênio se destacam, pois podem ocorrer como porfiroblastos. A textura em mosaico, formada por minerais pseudo-hexagonais, é encontrada generalizadamente (figura $3 \mathrm{c}, \mathrm{d}$ ). A composição mineral modal dos anfibolitos (tabela 1) engloba anfibólio, clinopiroxênio, plagioclásio, opacos, granada, carbonatos e titanita.

Anfibólio $\mathrm{O}$ anfibólio ocorre de duas formas: disperso, ou nas bordas do clinopiroxênio, semi-englobando este mineral e é representado por actinolita e hornblenda. A forma dos cristais de hornblenda é irregular, anedral a subedral prismática, muitos cristais são pseudo-hexagonais. A forma da hornblenda actinolín tica é mais anedral, irregular a fibrosa.

$\mathrm{O}$ anfibólio é fortemente pleocróico. A cor varia de marrom a verde escuro (hornblenda), sendo homogênea para um mesmo cristal. Estes cristais são os dominantes, mas ocorre anfibólio de coloração verde claro (actinolita) nas bordas dos cristais de cor mais forte, mas em maior proporção associada às bordas, fraturas e inclusões no clinopiroxênio.

Os limites dos cristais de anfibólio são bem definidos, tanto com os demais minerais, quanto entre si. $O$ formato dos contatos é irregular, arredondado, suavizado, reentrante poligonal ou reto (figura 3c). Os contatos são mais reentrantes com o clinopiroxênio e opacos; com o plagioclásio, são observados contatos de ambas as formas.

A alteração principal é para epidoto, especialmente entre as clivagens e fraturas. Outra forma de alteração é a sua perda de coloração, gradando de cores fortes para verde claro, caracterizando passagem de magnésio-hornblenda para actinolita, ou hornblenda actinolítica.

As inclusões na hornblenda são raras e tipicamente titanita, plagioclásio, opacos, raramente quartzo e, mais raramente ainda, biotita.

O aspecto deformacional apresentado pelo anfibólio é a presença de extinção ondulante e do seu forte estado de fraturamento. Estas fraturas apresentam abertura submilimétrica, em distribuição caótica e espaçamento irregular; quando há preenchimento, quase sempre é epidoto, mas pode conter opacos, carbonato ou clorita, individualmente.

Plagioclásio O plagioclásio é tipicamente labradorita a bytownita, ocorrendo mais raramente anortita. As formas dos cristais são anedrais, arredondadas ou angulosas, ovaladas e algumas formas pseudo-hexagonais (figura 3d). É um dos minerais que marcam a foliação com suas formas ovaladas, ou como agregados orientados. O tipo de contato mais comum é o arredondado.
Pode apresentar, ou não, geminação, que normalmente é tipo albita. De rocha para rocha a presença da geminação pode variar, tendo algumas quase todos os cristais geminados, especialmente os mais cálcicos, e outras onde o plagioclásio raramente apresenta esta estrutura. É comum o plagioclásio apresentar-se zonado, com o núcleo mais cálcico.

O estado de alteração do plagioclásio é baixo. Algumas vezes pode estar manchado, ou venulado por feldspato potássico. O mais comum é que ocorra a epidotização e a liberação de carbonatos (calcita).

Os maiores cristais frequentemente estão subdivididos em formatos pseudo-hexagonais, caracterizando um estágio em crescimento normal, ou recristalização primária. Os minerais microfraturados algumas vezes desenvolvem subgrãos nas paredes das fraturas e kink bands. Muitos cristais exibem forte extinção ondulante.

Clinopiroxênio $O$ clinopiroxênio não ocorre em todas as seções delgadas. São cristais totalmente anedrais e microfraturados irregularmente. Os contatos são nítidos e reentrantes ondulados. O clinopiroxênio é incolor, de composição diopsídio, mas raramente apresenta pleocroismo suave, esverdeado claro, quando de composição salita. Frequentemente situam-se no interior da hornblenda, próximo ao núcleo deste outro mineral, permanecendo semi-englobado pelo anfibólio (figura 3e).

O tamanho do clinopiroxênio é variável, desde submilimétrico, podendo atingir um máximo de $4 \mathrm{~mm}$, sempre acompanhando a granulação geral da rocha. O contato normalmente é com anfibólio. Faz contato com os demais minerais como titanita, opacos e plagioclásio, entretanto, é difícil ocorrer, porque os cristais de anfibólio tendem a crescer nas suas bordas, delimitando o clinopiroxênio. O anfibólio assim desenvolvido, pode, ou não, acompanhar a orientação óptica do mineral interior. $O$ clinopiroxênio algumas vezes encontra-se pseudomorfisado para carbonato + actinolita, ou hornblenda actinolítica + epidoto (figura 3f).

Titanita A titanita forma cristais anedrais de cor castanha pálida, fracamente pleocróico. Este mineral ocorre como cristais livres, ou como inclusões, especialmente em hornblenda, e como núcleos, ou bordas principalmente de ilmenita, ou subordinadamente de magnetita. Altera-se para epidoto.

Opacos Os opacos estão representados principalmente por ilmenita. Subordinadamente ocorrem magnetita e pirita. São minerais anedrais. Estão frequentemente associados ao anfibólio e ao clinopiroxênio. A ilmenita ocorre livre, ou posicionada no núcleo, ou bordas de titanita, ou ainda intercrescida com a magnetita.

Granada A granada é rara. Este mineral foi encontrado associado ao plagioclásio e à hornblenda. A granada não faz contato com o clinopiroxênio em nenhuma porção da rocha. Ocorre de modo granular, extremamente fraturada, concentrada localmente. Exibe cor castanha pálida, rosada, formando porfiroblastos sin a tardi-tectônicos.

Outros minerais O quartzo ocorre como inclusões, ou tipicamente como venulações. Apresenta extinção ondulante severa. $\mathrm{O}$ feldspato potássico é raro. Ocorre como manchas, ou vênulas no plagioclásio e está associado às fraturas, ou entre interstícios dos cristais. A clorita ocorre como preenchimento de veios, associada ao quartzo e precipitada nos máficos. Exibe forte pleocroismo verde claro. A apatita ocorre como cristais euedrais a subedrais, prismáticos longos, em contatos retos, é incolor e está associada aos demais minerais da rocha, especialmente ao 
plagioclásio. Os hidróxidos ocorrem preenchendo fraturas e interstícios nos minerais.

Venulações A presença de microveios tardios nos anfibolitos é muito comum. Estas estruturas são preenchidas normalmente por quartzo ou epidoto, de diferentes tamanhos.

Entretanto, há outro tipo de veio, em contato irregular, pouco ondulado, localmente reentrante, que se distingue dos demais por conter minerais dos quais os anfibolitos são compostos; porém, em granulação muito superior. A hornblenda, por exemplo, chega a atingir um tamanho 10 vezes superior ao que apresenta no anfibolito. No geral, são rochas granoblásticas, equigranulares grossas, com uma média do tamanho dos cristais de $5 \mathrm{~mm}$. São anisotrópicas, apresentando uma foliação bem marcada, na forma de cristais ovalados e alinhados. No contato entre o veio e o anfibolito são encontrados os maiores cristais, de até $2 \mathrm{~cm}$, bem destacados dos demais, com crescimento paralelo ou transversal ao contato.

$O$ veio e o anfibolito são muito parecidos, excetuando-se o teor elevado de calcita e titanita e pelo tamanho dos cristais. Além do mais, a titanita é mais alaranjada-avermelhada, contrastando com a coloração pálida que apresenta no anfibolito. Outra característica deste mineral é ser mais subedral, apresentando formatos losangulares, e ser mais límpido, sem alteração, núcleos, ou bordas de ilmenita ou magnetita, embora a magnetita e a pirita façam parte da composição mineral dos veios.

Os minerais são extremamente fraturados. A geometria das fraturas é irregular, encontrando-se diversos tipos de traçados, desde retilínios, curvilínios e irregulares angulosos. A maioria das fraturas tem abertura muito pequena e parece estar vazia. A disposição destas estruturas é aleatória, descontínua, espaçadamente irregular, envolvendo todos os minerais. A família de juntas mais propensa à instalação destes veios é a que se encontra a $40^{\circ}$ da foliação.

\section{QUÍMICA MINERAL}

Foram obtidas as composições químicas do anfibólio, plagioclásio, granada e piroxênio de três amostras das ocorrências anfibolíticas de Ermida (SH-1a, $\mathrm{SH}-1 \mathrm{~b}$ e SH-4a). Estes resultados foram adquiridos por meio de microssonda eletrônica, para serem utilizados em cálculos geotermométricos e geobarométricos.

O anfibólio foi classificado segundo Leake (1978), porque esta classificação diferencia melhor os minerais e entra em acordo com as observações petrográficas, a despeito da classificação de Leake et al. (1997), bem mais simplificada, mas que agrupa diferentes minerais de diferentes aspectos texturais e composições químicas em um mesmo campo.

As fórmulas estruturais do anfibólio, que juntamente com os dados químicos podem ser vistos na tabela 2 , foram calculadas com base em 23 oxigênios e os valores de $\mathrm{Fe}^{+3}$ são médias entre os valores máximos e mínimos de $\mathrm{Fe}^{+3}$, assumindo-se um total de 13 cátions, excluindo $\mathrm{Ca}, \mathrm{Na}$ e $\mathrm{K}$ (13-CNK), como indicado em Schumacher (1991). Assim, os anfibólios das ocorrências anfibolíticas de Ermida são classificados como cálcicos (série actinolita-hornblenda), no diagrama que correlaciona os elementos $\mathrm{BNa}$ versus $(\mathrm{BCa}+\mathrm{BNa})$.

Ao microscópio ótico, os anfibólios são individualizados principalmente por exibir coloração variada, de marrom a verde claro, sendo os verdes e os marrons petrograficamente determinados como hornblenda, e os verdes mais claros, actinolita. Assim, estes tipos petrograficamente individualizados foram objeto de análise, para se verificar a diferença de seus parâmetros óticos são reflexo de variação química.

Após os cálculos estruturais e plotagem dos dados nos diagramas classificatórios, notou-se que diferenças na coloração do anfibólio refeletem mudanças composicionais neste mineral. Os cristais mais escuros (verdes ou marrons) são de composição magnésio-hornblenda até tschermakita, enquanto os cristais verdes mais claros são hornblenda actinolítica (figura 4). A actinolita determinada petrograficamente não foi analisada quimicamente devido ao seu pequeno tamanho. Além da diferença na classificação destes minerais, nota-se mais claramente que há relativa homogenização entre os resultados das hornblendas, em contraste com os resultados das actinolitas, onde os elementos mais marcantes são o aumento nos teores de $\mathrm{SiO}_{2}(>49 \%)$ e uma diminuição nos teores de $\mathrm{Al}_{2} \mathrm{O}_{3}(<6 \%)$ e $\mathrm{TiO}_{2}(<0,5 \%)$ (tabela 2 ).

O plagioclásio foi determinado por meio do microscópio ótico variando de labradorita até anortita. As análises via microssonda eletrônica confirmaram a determinação, detectandose cristais do início da labradorita, aproximadamente $\mathrm{An}_{50}$ até o limite final da anortita, $\mathrm{An}_{97}$ (figura 5). Os resultados das análises podem ser vistos na tabela 3 , onde o óxido que mais chama a atenção é o $\mathrm{Na}_{2} \mathrm{O}$, que na anortita é $<1 \%$, contrastando com os demais tipos.

A fórmula estrutural do clinopiroxênio foi calculada para 8 oxigênios e pode ser vista na tabela 4 . Segundo os diagramas $Q$ versus J e En-Fs-Wo de Morimoto (1988), o clinopiroxênio foi classificado como cálcico, do tipo diopsídio, com um cristal sendo augita (figura 6), o que não condiz com suas características ópticas, talvez reflexo do menor teor de $\mathrm{CaO}(12,911 \%$, tabela 4) que contrasta com as demais amostras $(>23 \%)$.

A composição da granada não pode ser obtida por meio do microscópio óptico, então procedeu-se à análise de microssonda. Aí se revelou que a composição deste mineral, com base em 24 oxigênios, é aproximadamente almandina ${ }_{51-60}$ grossulária $_{22}$ ${ }_{29}$ piropo $_{11-15}$ espessartita ${ }_{5-8}$, como pode ser visto na tabela 5.

Termobarometria e metamorfismo - resultado e discussão As análises de anfibólio e plagioclásio foram obtidas para serem utilizadas nos cálculos de temperatura segundo o método de Blundy e Holland (1990). Neste método são quantificadas as condições de temperatura necessárias para a troca edenítica $(\mathrm{Al} \leftrightarrow \mathrm{Si})$ no anfibólio. Estes autores desenvolveram o termômetro associando o conteúdo de $\mathrm{Al}^{\mathrm{IV}}$ do anfibólio e a fração molar da albita coexistentes em rochas com sílica saturada. A calibração se baseia nas reações:

$$
\mathrm{Ed}+\mathrm{Qtz}=\mathrm{Tr}+\mathrm{Ab}
$$

e

$$
\operatorname{Prg}+4 \mathrm{Qtz}=\mathrm{Hbl}+\mathrm{Ab}
$$

A temperatura é calculada a partir da fórmula:

$$
T=(0,677 P-48,98+Y) /(-0,0429-0,008314 \ln K)
$$

onde

$$
K=[(s i-4) /(8-S i)] X_{a b}
$$

P é pressão inferida em kbar; $T$ é a temperatura obtida em Kelvin; $Y=0$ quando $X_{a b}>0,5$, ou

$$
Y=-8,06+25,5\left(1-X_{a b}\right) 2 \text {, se } X_{a b}<0,5
$$

e Si é o número de átomos por unidade de fórmula.

O método geobarométrico de Kohn \& Spear $(1989,1990)$, utilizando os pares granada-plagioclásio-anfibólio, foi definido com base no equilíbrio de duas reações: 
Tabela 2 - Composição química de anfibólios obtido por microssonda eletrônica e fórmula estrutural destes minerais com base em 23 oxigênios.

\begin{tabular}{|c|c|c|c|c|c|c|c|}
\hline Amostras & SH-1a & SH-1a & SH-1a & SH-1a & SH-1a & SH-1a & SH-1a \\
\hline Análise & 20.029 & 34.579 & 35.523 & 38.642 & 39.052 & 40.669 & 40.762 \\
\hline Posição & núcleo & núcleo & núcleo & núcleo & núcleo & núcleo & borda \\
\hline Classificação & Mg-hbl & act-hbl & Mg-hbl & Mg-hbl & Mg-hb] & Mg-hbl & Mg-hbl \\
\hline $\mathrm{SiO}_{2}$ & 43.985 & 50.019 & 44.491 & 46.173 & 44.132 & 44.531 & 45.827 \\
\hline $\mathrm{TiO}_{2}$ & 1.079 & 0.195 & 1.083 & 1.174 & 1.712 & 1.447 & 1.220 \\
\hline $\mathrm{Al}_{2} \mathrm{O}_{3}$ & 11.083 & 5.044 & 10.384 & 8.976 & 10.311 & 10.445 & 9.421 \\
\hline $\mathrm{FeO}$ & 19.929 & 19.180 & 20.265 & 16.947 & 17.238 & 18.825 & 17.759 \\
\hline $\mathrm{MnO}$ & 0.294 & 0.273 & 0.332 & 0.238 & 0.283 & 0.293 & 0.214 \\
\hline $\mathrm{MgO}$ & 8.683 & 11.315 & 8.778 & $10 . .615$ & 10.030 & 9.569 & 9.613 \\
\hline $\mathrm{CaO}$ & 10.897 & 11.680 & 10.919 & 11.652 & 11.316 & 11.442 & 11.269 \\
\hline $\mathrm{Na}_{2} \mathrm{O}$ & 1.307 & 0.359 & 1.132 & 1.114 & 1.389 & 1.316 & 1.131 \\
\hline $\mathrm{K}_{2} \mathrm{O}$ & 0.248 & 0.077 & 0.232 & 0.231 & 0.243 & 0.259 & 0.203 \\
\hline $\mathrm{F}$ & 0.019 & 0.000 & 0.006 & 0.048 & 0.017 & 0.093 & 0.000 \\
\hline $\mathrm{Cl}$ & 0.063 & 0.023 & 0.059 & 0.033 & 0.054 & 0.054 & 0.050 \\
\hline Total & 97.59 & 98.16 & 97.68 & 97.20 & 96.72 & 98.27 & 96.71 \\
\hline $\mathrm{TSi}$ & 6.579 & 7.330 & 6.644 & 6.870 & 6.624 & $6 . .608$ & 6.878 \\
\hline TAl & 1.421 & 0.670 & 1.356 & 1.130 & 1.376 & 1.392 & 1.122 \\
\hline $\mathrm{TFe}^{+3}$ & 0.000 & 0.000 & 0.000 & 0.000 & 0.000 & 0.000 & 0.000 \\
\hline TTi & 0.000 & 0.000 & 0.000 & 0.000 & 0.000 & 0.000 & 0.000 \\
\hline Total & 8.000 & 8.000 & 8.000 & 8.000 & 8.000 & 8.000 & 8.000 \\
\hline $\mathrm{CAl}$ & 0.531 & 0.200 & 0.470 & 0.442 & 0.447 & 0.433 & 0.543 \\
\hline $\mathrm{CCr}$ & 0.000 & 0.000 & 0.000 & 0.000 & 0.000 & 0.000 & 0.000 \\
\hline $\mathrm{CFe}^{+3}$ & 0.490 & 0.488 & 0.540 & 0.223 & 0.289 & 0.401 & 0.222 \\
\hline $\mathrm{CTi}$ & 0.121 & 0.021 & 0.122 & 0.131 & 0.193 & 0.162 & 0.138 \\
\hline $\mathrm{CMg}$ & 1.936 & 2.472 & 1.954 & 2.354 & 2.244 & 2.117 & 2.151 \\
\hline $\mathrm{CFe}^{+2}$ & 1.903 & 1.802 & 1.894 & 1.834 & 1.809 & 1.869 & 1.933 \\
\hline $\mathrm{CMn}$ & 0.018 & 0.017 & 0.021 & 0.015 & 0.018 & 0.018 & 0.014 \\
\hline $\mathrm{CCa}$ & 0.000 & 0.000 & 0.000 & 0.000 & 0.00 & 0.000 & 0.000 \\
\hline Total & 5.000 & 5.000 & 5.000 & 5.000 & 5.000 & 5.000 & 5.000 \\
\hline $\mathrm{BMg}$ & 0.000 & 0.000 & 0.000 & 0.000 & 0.000 & 0.000 & 0.000 \\
\hline $\mathrm{BFe}^{+2}$ & 0.100 & 0.061 & 0.097 & 0.052 & 0.066 & 0.066 & 0.074 \\
\hline BMn & 0.019 & 0.017 & 0.021 & 0.015 & 0.018 & 0.019 & 0.014 \\
\hline $\mathrm{BCa}$ & 1.746 & 1.834 & 1.747 & 1.857 & 1.820 & 1.819 & 1.812 \\
\hline $\mathrm{BNa}$ & 0.135 & 0.051 & 0.134 & 0.076 & 0.096 & 0.096 & 0.100 \\
\hline Total & 2.000 & 1.962 & 2.000 & 2.000 & 2.000 & 2.000 & 2.000 \\
\hline $\mathrm{ACa}$ & 0.000 & 0.000 & 0.000 & 0.000 & 0.000 & 0.000 & 0.000 \\
\hline $\mathrm{ANa}$ & 0.244 & 0.051 & 0.193 & 0.245 & 0.308 & 0.282 & 0.229 \\
\hline $\mathrm{AK}$ & 0.047 & 0.014 & 0.044 & 0.044 & 0.047 & 0.049 & 0.039 \\
\hline Total & 0.292 & 0.066 & 0.238 & 0.289 & 0.355 & 0.331 & 0.268 \\
\hline $\begin{array}{l}\text { Total dos } \\
\text { cátions }\end{array}$ & 15.292 & 15.028 & 15.238 & 15.289 & 15.355 & 15.331 & 15.268 \\
\hline $\mathrm{CCl}$ & 0.016 & 0.006 & 0.015 & 0.008 & 0.014 & 0.014 & 0.013 \\
\hline $\mathrm{CF}$ & 0.009 & 0.000 & 0.003 & 0.023 & 0.008 & 0.044 & 0.000 \\
\hline $\mathrm{OH}$ & - & 0.000 & 0.000 & 0.000 & 0.000 & 0.000 & 0.000 \\
\hline $\begin{array}{l}\text { Total dos } \\
\text { oxigênios }\end{array}$ & 23.000 & 23.000 & 23.000 & 23.000 & 23.003 & 23.000 & 23.043 \\
\hline
\end{tabular}

$6 \mathrm{An}+3 \mathrm{Tr}=2 \mathrm{Grs}+\operatorname{Prp}+3 \mathrm{Ts}+6 \mathrm{Qtz}$

$$
6 \mathrm{An}+3 \mathrm{Fe} \_\mathrm{Act}=2 \mathrm{Grs}+\mathrm{Alm}+3 \mathrm{Fe} \mathrm{Ts}_{-}+18 \mathrm{Qtz}
$$

Os valores de pressão são definidos a partir de valores de temperatura estimados, a partir da fórmula:

$$
-R T \ln K_{e q}=A-B T+(P C)
$$

$$
K_{e q}=\left[(a G r s) 2\left(a P_{r p}\right)(a T s) 3(a Q z) /(a A n) 6(a T r)\right]
$$

ou

$$
K_{e q}=\left[(a \mathrm{Grs}) 2(a \mathrm{Alm})\left(a \mathrm{Fe} \_\mathrm{Ts}\right) 3(a \mathrm{Qtz}) /(a \mathrm{An}) 6(a \mathrm{Fe} A c t)\right](6)
$$

As abreviaturas dos minerais são de acordo com Kretz (1983).

A seleção dos métodos baseou-se nos minerais encontrados nos anfibolitos e que estão em equilíbrio entre si. Os minerais típicos do equilíbrio do pico metamórfico são as associações (1) clinopiroxênio + hornblenda + plagioclásio + ilmenita e (2) hornblenda + plagioclásio + ilmenita + granada.

A ausência de relações de contato entre granada e clinopiroxênio inviabiliza utilizar métodos geotermobarométricos que incluam estes dois minerais, mas o método geobarométrico de Kohn \& Spear $(1989,1990)$ pode ser utilizado para estimar a pressão, porque a granada está em equilíbrio com o plagioclásio e com o anfibólio. Os resultados dos cálculos geotermobaromé- 
Tabela 2 - Continuação

\begin{tabular}{|c|c|c|c|c|c|c|c|}
\hline Amostras & SH-1a & SH-1a & SH-1a & SH-1b & SH-1b & SH-1b & SH-1b \\
\hline Análise & 49.316 & 49.339 & 50.826 & 39.785 & 40.104 & 44.413 & 45.030 \\
\hline Posição & borda & borda & borda & borda & borda & núcleo & núcleo \\
\hline Classificação & Mg-hbl & $\mathrm{Mg}-\mathrm{hbl}$ & Mg-hbl & $\mathrm{tsh}$ & act-hbl & tsh & tsh \\
\hline $\mathrm{SiO}_{2}$ & 43.780 & 44.641 & 44.880 & 42.219 & 49.420 & 41.774 & 41.519 \\
\hline $\mathrm{TiO}_{2}$ & 1.371 & 1.187 & 1.073 & 1.523 & 0.333 & 0.986 & 1.117 \\
\hline $\mathrm{Al}_{2} \mathrm{O}_{3}$ & 10.892 & 9.729 & 9.476 & 14.023 & 5.910 & 16.014 & 14.242 \\
\hline $\mathrm{FeO}$ & 19.468 & 19.986 & 18.658 & 15.988 & 15.629 & 16.434 & 16.658 \\
\hline $\mathrm{MnO}$ & 0.383 & 0.364 & 0.324 & 0.228 & 0.333 & 0.290 & 0.300 \\
\hline $\mathrm{MgO}$ & 8.618 & 9.103 & 9.758 & 9.988 & 12.155 & 9.135 & 9.647 \\
\hline $\mathrm{CaO}$ & 11.010 & 11.243 & 11.051 & 11.776 & 12.335 & 11.915 & 11.616 \\
\hline $\mathrm{Na}_{2} \mathrm{O}$ & 1.239 & 1.005 & 1.308 & 1.606 & 0.484 & 1.582 & 1.766 \\
\hline $\mathrm{K}_{2} \mathrm{O}$ & 0.257 & 0.237 & 0.216 & 0.414 & 0.232 & 0.321 & 0.321 \\
\hline F & 0.109 & 0.000 & 0.088 & 0.000 & 0.000 & 0.000 & 0.015 \\
\hline $\mathrm{Cl}$ & 0.072 & 0.065 & 0.054 & 0.041 & 0.017 & 0.062 & 0.040 \\
\hline Total & 97.20 & 97.56 & 96.81 & 97.81 & 96.85 & 98.51 & 97.24 \\
\hline $\mathrm{TSi}$ & 6.588 & 6.673 & 6.733 & 6.243 & 7.304 & 6.131 & 6.187 \\
\hline TAl & 1.412 & 1.327 & 1.267 & 1.757 & 0.696 & 1.869 & 1.813 \\
\hline $\mathrm{TFe}^{+3}$ & 0.000 & 0.000 & 0.000 & 0.000 & 0.000 & 0.000 & 0.000 \\
\hline TTi & 0.000 & 0.000 & 0.000 & 0.000 & 0.000 & 0.000 & 0.000 \\
\hline Total & 8.000 & 8.000 & 8.000 & 8.000 & 8.000 & 8.000 & 8.000 \\
\hline $\mathrm{CAl}$ & 0.518 & 0.386 & 0.410 & 0.685 & 0.333 & 0.898 & 0.686 \\
\hline $\mathrm{CCr}$ & 0.000 & 0.000 & 0.000 & 0.000 & 0.000 & 0.000 & 0.000 \\
\hline $\mathrm{CFe}^{+3}$ & 0.412 & 0.549 & 0.427 & 0.337 & 0.156 & 0.378 & 0.461 \\
\hline CTi & 0.155 & 0.133 & 0.121 & 0.169 & 0.037 & 0.109 & 0.125 \\
\hline $\mathrm{CMg}$ & 1.933 & 2.029 & 2.186 & 2.202 & 2.678 & 1.999 & 2.143 \\
\hline $\mathrm{CFe}^{+2}$ & 1.957 & 1.880 & 1.835 & 1.592 & 1.775 & 1.598 & 1.566 \\
\hline $\mathrm{CMn}$ & 0.024 & 0.023 & 0.020 & 0.014 & 0.021 & 0.018 & 0.019 \\
\hline $\mathrm{CCa}$ & 0.000 & 0.000 & 0.000 & 0.000 & 0.000 & 0.000 & 0.000 \\
\hline Total & 5.000 & 5.000 & 5.000 & 5.000 & 5.000 & 5.000 & 5.000 \\
\hline $\mathrm{BMg}$ & 0.000 & 0.000 & 0.000 & 0.000 & 0.000 & 0.000 & 0.000 \\
\hline $\mathrm{BFe}^{+2}$ & 0.081 & 0.070 & 0.083 & 0.048 & 0.001 & 0.041 & 0.049 \\
\hline BMn & 0.025 & 0.023 & 0.021 & 0.014 & 0.021 & 0.018 & 0.019 \\
\hline $\mathrm{BCa}$ & 1.775 & 1.801 & 1.779 & 1.866 & 1.953 & 1.874 & 1.855 \\
\hline $\mathrm{BNa}$ & 0.120 & 0.106 & 0.117 & 0.072 & 0.025 & 0.067 & 0.078 \\
\hline Total & 2.000 & 2.000 & 2.000 & 2.000 & 2.000 & 2.000 & 2.000 \\
\hline $\mathrm{ACa}$ & 0.000 & 0.000 & 0.000 & 0.000 & 0.000 & 0.000 & 0.000 \\
\hline $\mathrm{ANa}$ & 0.242 & 0.185 & 0.264 & 0.389 & 0.114 & 0.383 & 0.433 \\
\hline $\mathrm{AK}$ & 0.049 & 0.045 & 0.041 & 0.078 & 0.044 & 0.060 & 0.061 \\
\hline Total & 0.291 & 0.231 & 0.305 & 0.467 & 0.157 & 0.443 & 0.494 \\
\hline $\begin{array}{l}\text { Total dos } \\
\text { cátions }\end{array}$ & 15.291 & 15.231 & 15.305 & 15.467 & 15.157 & 15.443 & 15.494 \\
\hline $\mathrm{CCl}$ & 0.018 & 0.016 & 0.014 & 0.010 & 0.004 & 0.015 & 0.010 \\
\hline $\mathrm{CF}$ & 0.052 & 0.000 & 0.042 & 0.000 & 0.000 & 0.000 & 0.007 \\
\hline $\mathrm{OH}$ & 0.000 & 0.000 & 0.000 & 0.000 & 0.000 & 0.000 & 0.000 \\
\hline $\begin{array}{l}\text { Total dos } \\
\text { oxigênios }\end{array}$ & 23.000 & 23.000 & 23.000 & 23.000 & 23.000 & 23.000 & 23.000 \\
\hline
\end{tabular}

tricos podem ser vistos relacionados nas tabelas 6 e 7

O metamofismo que afetou os protólitos dos anfibolitos é de carácter regional. Observa-se pela descrição petrográfica que há a formação de duas paragêneses distintas indicando um pico metamórfico $\left(\mathrm{M}_{1}\right)$ e um retrometamorfismo $\left(\mathrm{M}_{2}\right)$, correlacionadas às fases $D_{n-1} / D_{n}$ e $D_{n+1} / D_{n+3}$ (Hackspacher et al. 1996).

A presença de textura em mosaico, indicando recristalização primária dos minerais, sugere que a temperatura tenha sido elevada.

PICO DO METAMORFISMO Em $\mathrm{M}_{1}$ formou-se as paragêneses clinopiroxênio (diopsídio, ou salita) + plagioclásio (labradorita a anortita) + anfibólio (magnésio hornblenda a tschermakita) + ilmenita + quartzo; na fase mais tardia desenvolvem-se ilmenita + quartzo + plagioclásio + anfibólio + granada, sem cli- nopiroxênio. A presença destas paragêneses de $\mathrm{Ml}$ e a presença de sillimanita nos gnaisses encaixantes permitem situar as condições de metamorfismo em facies anfibolito, zona da sillimanita. A quantificação das condições de temperatura e pressão de $\mathrm{M}_{1}$ pela associação anfibólio-plagioclásio, calibrado para as substituições edeníticas, proveu resultados entre $700^{\circ}$ e $830^{\circ} \mathrm{C}$, com pressões estimadas entre 6 e $7 \mathrm{kbar}$, associando-se os métodos de Kohn \& Spear $(1989,1990)$ e Blundy \& Holland (1990) (tabelas 6 e 7). Estes resultados permitem estabelecer que a profundidade do soterramento a qual estas rochas foram submetidas foi de, no mínimo, $22 \mathrm{~km}$, admitindo-se o gradiente barométrico de $0,27 \mathrm{kbar} / \mathrm{km}$ e o gradiente geotérmico de $33^{\circ} \mathrm{C} / \mathrm{km}$.

Comparando os resultados obtidos com o intervalo de cristalização do granito Nazaré Paulista, que é tido como produto de anatexia das rochas metassedimentares e está entre $680^{\circ} \mathrm{e}$ 
Tabela 2 - Continuação

\begin{tabular}{|c|c|c|c|c|c|}
\hline Amostras & SH-1b & SH-1b & SH-4a & SH-4a & SH-4a \\
\hline Análise & 54.159 & 54.435 & 16.226 & 16.243 & 16.318 \\
\hline Posição & núcleo & borda & borda & núcleo & núcleo \\
\hline Classificação & tsh-hbl & Mg-hbl & Mg-hbl & Mg-hbl & $\mathrm{Mg}-\mathrm{hbl}$ \\
\hline $\mathrm{SiO}_{2}$ & 43.428 & 44.905 & 44.283 & 44.190 & 44.079 \\
\hline $\mathrm{TiO}_{2}$ & 0.766 & 0.639 & 1.435 & 1.357 & 1.446 \\
\hline $\mathrm{Al}_{2} \mathrm{O}_{3}$ & 13.712 & 11.428 & 10.738 & 10.325 & 10.197 \\
\hline $\mathrm{FeO}$ & 14.927 & 15.033 & 17.365 & 17.339 & 17.226 \\
\hline $\mathrm{MnO}$ & 0.216 & 0.284 & 0.281 & 0.324 & 0.264 \\
\hline $\mathrm{MgO}$ & 11.053 & 11.499 & 10.383 & 10.588 & 10.639 \\
\hline $\mathrm{CaO}$ & 11.998 & 12.091 & 11.030 & 11.084 & 10.961 \\
\hline $\mathrm{Na}_{2} \mathrm{O}$ & 1.587 & 1.235 & 1.349 & 1.279 & 1.193 \\
\hline $\mathrm{K}_{2} \mathrm{O}$ & 0.325 & 0.289 & 0.205 & 0.186 & 0.215 \\
\hline $\mathrm{F}$ & 0.055 & 0.111 & 0.074 & 0.000 & 0.006 \\
\hline $\mathrm{Cl}$ & 0.062 & 0.039 & 0.049 & 0.046 & 0.031 \\
\hline Total & 98.13 & 97.55 & 97.19 & 96.72 & 96.26 \\
\hline TSi & 6.350 & 6.597 & 6.581 & 6.587 & $6 . .594$ \\
\hline TAl & 1.650 & 1.403 & 1.419 & 1.413 & 1.406 \\
\hline $\mathrm{TFe}^{+3}$ & 0.000 & 0.000 & 0.000 & 0.000 & 0.000 \\
\hline TTi & 0.000 & 0.000 & 0.000 & 0.000 & 0.000 \\
\hline Total & 8.000 & 8.000 & 8.000 & 8.000 & 8.000 \\
\hline $\mathrm{CAl}$ & 0.711 & 0.574 & 0.460 & 0.400 & 0.390 \\
\hline $\mathrm{CCr}$ & 0.000 & 0.000 & 0.000 & 0.000 & 0.000 \\
\hline $\mathrm{CFe}^{+3}$ & 0.389 & 0.385 & 0.470 & 0.547 & 0.562 \\
\hline $\mathrm{CTi}$ & 0.084 & 0.071 & 0.160 & 0.152 & 0.163 \\
\hline $\mathrm{CMg}$ & 2.409 & 2.518 & 2.300 & 2.353 & 2.373 \\
\hline $\mathrm{CFe}^{+2}$ & 1.393 & 1.434 & 1.592 & 1.527 & 1.496 \\
\hline $\mathrm{CMn}$ & 0.013 & 0.018 & 0.018 & 0.020 & 0.017 \\
\hline $\mathrm{CCa}$ & 0.000 & 0.000 & 0.000 & 0.000 & 0.000 \\
\hline Total & 5.000 & 5.000 & 5.000 & 5.000 & 5.000 \\
\hline $\mathrm{BMg}$ & 0.000 & 0.000 & 0.000 & 0.000 & 0.000 \\
\hline $\mathrm{BFe}^{-12}$ & 0.043 & 0.027 & 0.096 & 0.087 & 0.097 \\
\hline $\mathrm{BMn}$ & 0.013 & 0.018 & 0.018 & 0.021 & 0.017 \\
\hline $\mathrm{BCa}$ & 1.880 & 1.903 & 1.756 & 1.770 & 1.757 \\
\hline $\mathrm{BNa}$ & 0.064 & 0.052 & 0.130 & 0.122 & 0.129 \\
\hline Total & 2.000 & 2.000 & 2.000 & 2.000 & 2.000 \\
\hline $\mathrm{ACa}$ & 0.000 & 0.000 & 0.000 & 0.000 & 0.000 \\
\hline $\mathrm{ANa}$ & 0.386 & 0.300 & 0.259 & 0.248 & 0.217 \\
\hline $\mathrm{AK}$ & 0.061 & 0.054 & 0.039 & 0.035 & 0.041 \\
\hline Total & 0.446 & 0.354 & 0.298 & 0.283 & 0.258 \\
\hline $\begin{array}{l}\text { Total dos } \\
\text { cátions }\end{array}$ & 15.446 & 15.354 & 15.298 & 15.283 & 15.258 \\
\hline $\mathrm{CCl}$ & 0.01 & 0.010 & 0.012 & 0.012 & 0.008 \\
\hline $\mathrm{CF}$ & 0.025 & 0.052 & 0.035 & 0.000 & 0.003 \\
\hline $\mathrm{OH}$ & 0.000 & 0.000 & 0.000 & 0.000 & 0.000 \\
\hline $\begin{array}{l}\text { Total dos } \\
\text { oxigênios }\end{array}$ & 23.000 & 23.000 & 23.000 & 23.000 & 23.000 \\
\hline
\end{tabular}

$720^{\circ} \mathrm{C}$ (Wernick et al. 1987 ), e cristalizou-se a uma temperatura inferior a da anatexia das rochas metassedimentares; portanto, a temperatura do metamorfismo deve estar acima de $720^{\circ} \mathrm{C}$.

As temperaturas obtidas para a associação do pico do metamorfismo $\left(700-830^{\circ}, 6-7 \mathrm{kbar}\right)$ são superiores às determinadas por Ghent et al. (1977), Guidotti (1970), Atzori et al. (1984) e Leite \& Lima (1991) para anfibolitos semelhantes à Ermida e para a porção superior da facies anfibolito e zona da sillimanita, onde indicam um máximo de $690^{\circ} \mathrm{C}$. Contudo, os valores são semelhantes aos encontrados em Souza (1997) para anfibolitos de ocorrência dispersa no Complexo Itapira na folha Cabreúva, até $860^{\circ} \mathrm{C}$. As temperaturas ao redor do limite superior determinado para os anfibolitos de Ermida foram encontradas por Bingen et al. (1984), Rollinson (1981), Green \& Adam (1991) em associações em facies granulito
As temperaturas encontradas, até $830^{\circ} \mathrm{C}$, sugerem que estes anfibolitos alcançaram condições de temperatura transicionais para a facies granulito (Souza 1997; Souza \& Oliveira 1998), como no intervalo considerado entre $725^{\circ}$ e $836^{\circ} \mathrm{C}$ por Broekmans et al. (1994). Contudo, apesar das elevadas temperaturas determinadas para os anfibolitos de Ermida (até $830^{\circ} \mathrm{C}$ ) o ortopiroxênio não se formou, embora, segundo Spear (1981), o aparecimento do ortopiroxênio devesse ocorrer entre $768^{\circ}$ e $788^{\circ} \mathrm{C}$, $1 \mathrm{kbar}$. A ausência do ortopiroxênio generalizadamente talvez deva-se às condições hídricas do metamorfismo, favorecendo a anatexia, que se reflete em vênulas, veios e até corpos de composição granítica leucocrática, com ou sem granada (Granito Nazaré Paulista). O Complexo Itapira na região de Atibaia apresenta granulitos verdadeiros, onde está presente o hiperstênio. Isto indica que localmente a desidratação ocorreu, e, consequen- 


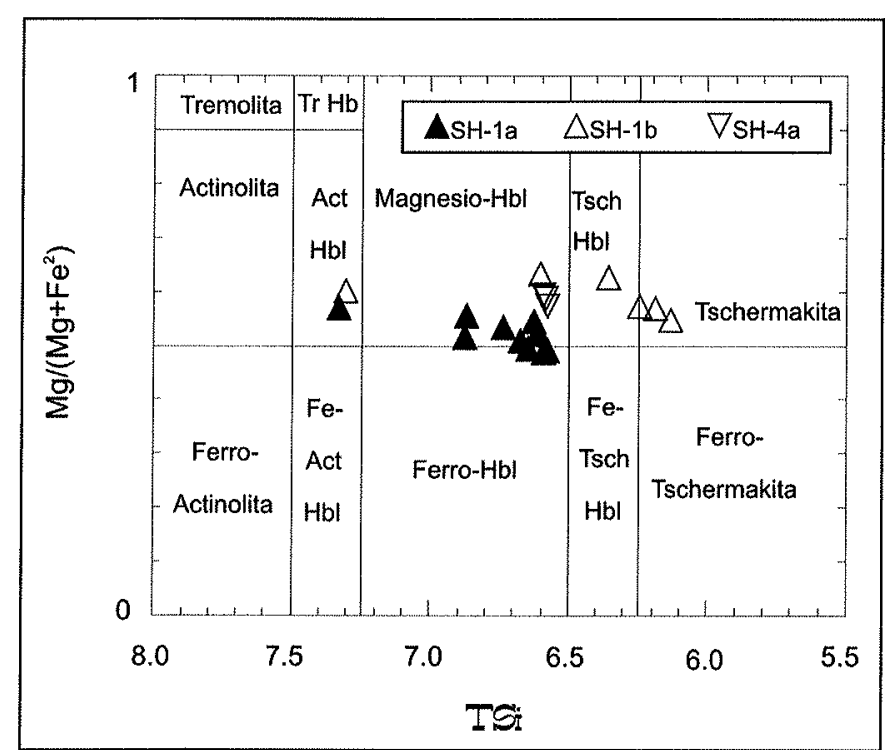

Figura 4 - Classificação dos anfibólios das ocorrências anfiboliticas de Ermida no diagrama $\mathrm{Mg} /\left(\mathrm{Mg}+\mathrm{Fe}^{+2}\right) \times \mathrm{TSi}$, de Leake (1978).

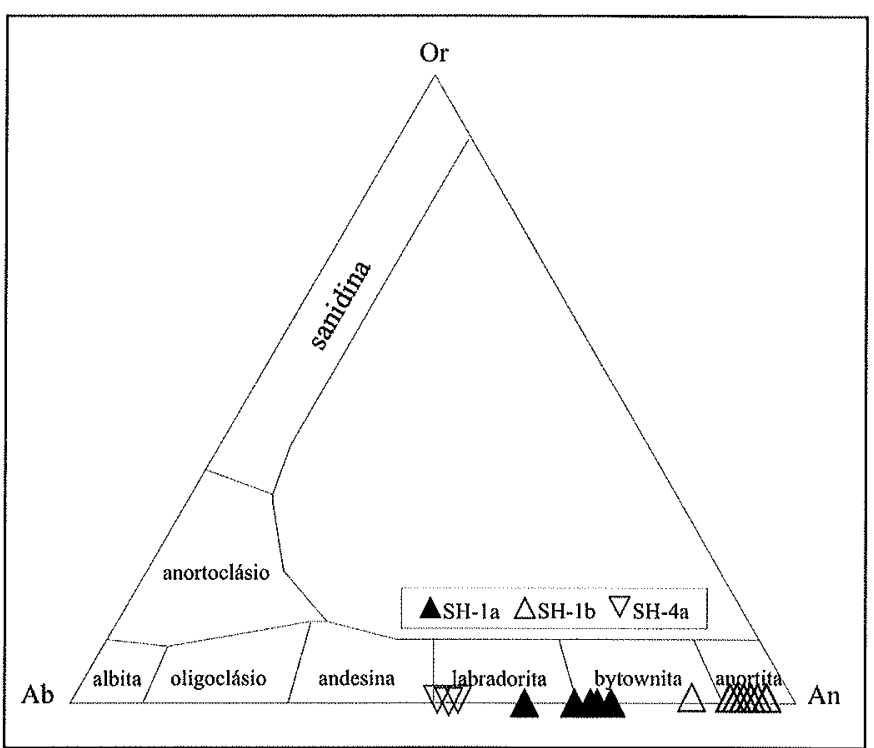

Figura 5 - Classificação dos plagioclásios das ocorrências anfibolíticas de Ermida, segundo o diagrama Ab-An-Or, apresentando moderada variação na composição deste mineral.

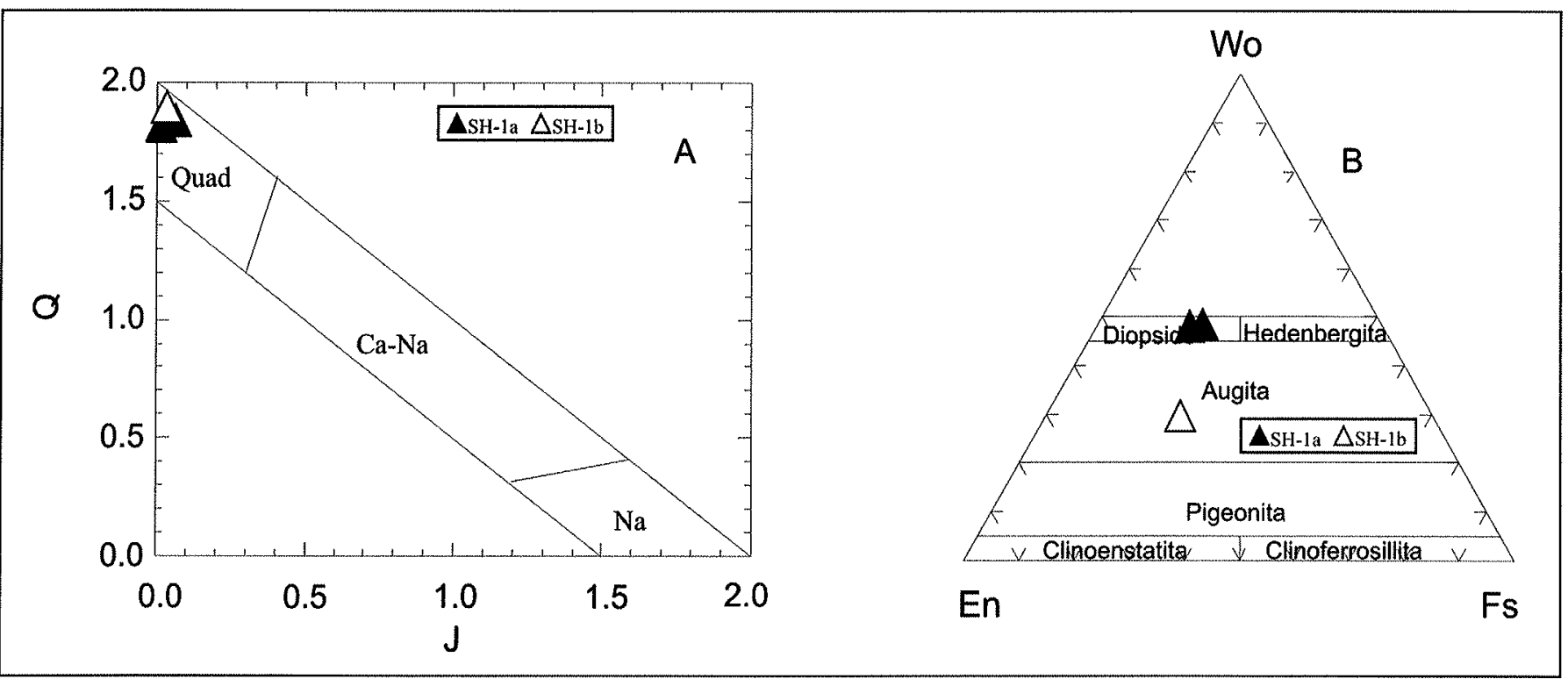

Figura 6 - Classificação dos piroxênios das ocorrências anfiboliticas de Ermida, nos diagramas $Q \times J(A)$ e En-Fs-Wo (B), de Morimoto (1988).

temente a facies granulito.

$\mathrm{Na}$ realidade, a associação mineral indica a condição da facies em que as rochas se encontram, os valores determinados pela termobarometria limitam os intervalos de temperatura em que esta associação pode ocorrer. Neste caso, aparentemente está se expandindo o intervalo de formação da associação clinopiroxênio, plagioclásio, anfibólio, ilmenita e quartzo, em facies anfibolito, para até $830^{\circ} \mathrm{C}$, que normalmente adentra o intervalo onde seria esperada a formação de associações minerais em $f a-$ cies granulito.

O RETROMETAMORFISMO As evidências de retrometamorfismo (M2) são a recristalização de actinolita ou hornblenda actinolítica nas bordas do clinopiroxênio, bem como pela presença de actinolita, carbonato e epidoto entre as fraturas e cliva- gens deste mesmo mineral, a recristalização de epidoto a partir de plagioclásio e hornblenda actinolítica e actinolita a partir da hornblenda.

O retrometamorfismo não foi quantificado. O aparecimento da hornblenda actinolítica nesta fase sugere condições de transição da facies xisto verde para a facies anfibolito. As condições estimadas para esta fase são de $450^{\circ}$ a $550^{\circ} \mathrm{C}$, de 2 a $4 \mathrm{kbar}$, ocorrido provavelmente a $7 \mathrm{~km}$ de profundidade, de acordo com os experimentos de Kostyuk \& Sobolev (1969) e Liou et al. (1974), embora Frimmel \& Hartnardy (1992) indiquem que esta zona de transição esteja entre $500^{\circ}$ e $600^{\circ} \mathrm{C}$.

CONCLUSÕES Os dados petrográficos determinam as paragêneses e as condições microestruturais dos minerais presentes nos anfibolitos de Ermida, correlacionadas ao pico me- 
Tabela 3 - Composição química de plagioclásio obtida por microssonda eletrônica e fórmula estrutural calculada com base em 32 oxigênios.

\begin{tabular}{|c|c|c|c|c|c|c|c|c|}
\hline Amostras & SH-1a & SH-1a & SH-1a & SH-1a & SH-1a & SH-1a & SH-1b & SH-1b \\
\hline Análise & 39.053 & 39.139 & 41.091 & 49.302 & 49.408 & 51.024 & 01 & 02 \\
\hline Posição & núcleo & borda & núcleo & núcleo & borda & núcleo & borda & borda \\
\hline Classificação & labradorita & bytownita & labradorita & bytownita & bytownita & bytownita & anortita & anortita \\
\hline $\mathrm{SiO}_{2}$ & 50.905 & 50.437 & 53.122 & 50.141 & 49.437 & 50.443 & 44.750 & 44.837 \\
\hline $\mathrm{TiO}_{2}$ & 0.000 & 0.065 & 0.000 & 0.000 & 0.031 & 0.000 & 0.000 & 0.000 \\
\hline $\mathrm{Al}_{2} \mathrm{O}_{3}$ & 31.574 & 32.225 & 30.627 & 32.333 & 32.244 & 31.983 & 35.788 & 35.290 \\
\hline $\mathrm{Fe}_{2} \mathrm{O}_{3}$ & 0.000 & 0.000 & 0.000 & 0.000 & 0.000 & 0.000 & 0.000 & 0.000 \\
\hline $\mathrm{FeO}$ & 0.125 & 0.111 & 0.052 & 0.139 & 0.106 & 0.112 & 0.065 & 0.153 \\
\hline $\mathrm{MnO}$ & 0.004 & 0.017 & 0.012 & 0.020 & 0.000 & 0.014 & 0.017 & 0.000 \\
\hline $\mathrm{MgO}$ & 0.017 & 0.000 & 0.020 & 0.012 & 0.000 & 0.015 & 0.000 & 0.000 \\
\hline $\mathrm{BaO}$ & 0.012 & 0.019 & 0.002 & 0.149 & 0.000 & 0.000 & 0.000 & 0.000 \\
\hline $\mathrm{CaO}$ & 14.533 & 14.906 & 12.829 & 14.918 & 15.510 & 14.804 & 19.285 & 18.830 \\
\hline $\mathrm{Na}_{2} \mathrm{O}$ & 3.447 & 3.229 & 4.255 & 3.049 & 2.944 & 3.223 & 0.502 & 0.799 \\
\hline $\mathrm{K}_{2} \mathrm{O}$ & 0.007 & 0.029 & 0.028 & 0.022 & 0.014 & 0.024 & 0.001 & 0.010 \\
\hline TOTAL & 100.624 & 101.038 & 100.947 & 100.783 & 100.286 & 100.618 & 100.408 & 99.919 \\
\hline $\mathrm{Si}$ & 9.219 & 9.109 & 9.530 & 9.085 & 9.014 & 9.142 & 8.230 & 8.286 \\
\hline Al & 6.734 & 6.854 & 6.471 & 6.899 & 6.924 & 6.826 & 7.751 & 7.680 \\
\hline $\mathrm{Fe} 3$ & 0.000 & 0.000 & 0.000 & 0.000 & 0.000 & 0.000 & 0.000 & 0.000 \\
\hline $\mathrm{Ti}$ & 0.000 & 0.009 & 0.000 & 0.000 & 0.004 & 0.000 & 0.000 & 0.000 \\
\hline $\mathrm{Fe}^{+2}$ & 0.019 & 0.017 & 0.008 & 0.021 & 0.016 & 0.017 & 0.010 & 0.024 \\
\hline $\mathrm{Mn}$ & 0.001 & 0.003 & 0.002 & 0.003 & 0.000 & 0.002 & 0.003 & 0.000 \\
\hline $\mathrm{Mg}$ & 0.005 & 0.000 & 0.005 & 0.003 & 0.000 & 0.004 & 0.000 & 0.000 \\
\hline $\mathrm{Ba}$ & 0.001 & 0.001 & 0.000 & 0.011 & 0.000 & 0.000 & 0.000 & 0.000 \\
\hline $\mathrm{Ca}$ & 2.820 & 2.884 & 2.466 & 2.896 & 3.030 & 2.875 & 3.800 & 3.728 \\
\hline $\mathrm{Na}$ & 1.210 & 1.131 & 1.480 & 1.071 & 1.041 & 1.133 & 0.179 & 0.286 \\
\hline $\mathrm{K}$ & 0.002 & 0.007 & 0.006 & 0.005 & 0.003 & 0.006 & 0.000 & 0.002 \\
\hline $\begin{array}{l}\text { Soma dos } \\
\text { cátions }\end{array}$ & 20.012 & 20.016 & 19.968 & 20.005 & 20.032 & 20.005 & 19.973 & 20.006 \\
\hline $\mathrm{X}$ & 15.953 & 15.972 & 16.001 & 15.984 & 15.942 & 15.968 & 15.981 & 15.966 \\
\hline $\mathrm{Z}$ & 4.058 & 4.043 & 3.967 & 4.010 & 4.090 & 4.037 & 3.992 & 4.040 \\
\hline $\mathrm{Ab}$ & 30.0 & 28.1 & 37.4 & 27.0 & 25.6 & 28.2 & 4.5 & 7.1 \\
\hline An & 69.9 & 71.7 & 62.4 & 72.9 & 74.4 & 71.6 & 95.5 & 92.8 \\
\hline Or & 0.0 & 0.2 & 0.2 & 0.1 & 0.1 & 0.1 & 0.0 & 0.0 \\
\hline
\end{tabular}

tamórfico e ao retrometamorfismo, em um caminhamento $P-T$ horário (figura 7).

Os minerais em equilíbrio no pico metamórfico são clinopiroxênio (diopsídio ou salita) + plagioclásio (labradorita a anortita) + anfibólio (magnésio-hornblenda a tschermakita) + ilmenita + quartzo, num estágio inicial. Posteriormente, continuam se formando plagioclásio + anfibólio + ilmenita + quartzo + grana$\mathrm{da}$, sem clinopiroxênio, o que explica a falta de contato entre os dois últimos minerais. A textura granoblástica, freqüentemente, apresenta-se em mosaico, indicando estágio de recuperação e recristalização primária dos minerais.

A presença de sillimanita nas rochas metassedimentares e a associação mineral e a textura dos anfibolitos indicam que estas rochas estão em condições elevadas de temperatura, na facies anfibolito superior, zona da sillimanita.

A quantificação foi efetuada com base no método de Blundy \& Holland (1990) para o cálculo da temperatura e no método de Kohn \& Spear $(1989,1990)$ para o cálculo da pressão.

Os valores encontrados estão no intervalo de temperatura entre $700^{\circ}$ e $830^{\circ} \mathrm{C}$, e pressão entre 6 e $7 \mathrm{kbar}$. Estes dados permitem colocar a profundidade de soterramento de no mínimo $22 \mathrm{~km}$, admitindo-se o gradiente barométrico de $0,27 \mathrm{kbar} / \mathrm{km}$ e o gradiente geotérmico de $33^{\circ} \mathrm{C} / \mathrm{km}$.

Este intervalo de temperatura do metamorfismo está em acordo com o intervalo de cristalização do granito Nazaré Paulista (entre $680^{\circ}$ a $720^{\circ} \mathrm{C}$ ), que é tido como produto de anatexia das rochas metassedimentares do Complexo Itapira, sugerindo que a temperatura de metamorfismo deva ser mais elevada.

A formação das paragêneses de $M_{1}$, sob condições de temperatura entre $700^{\circ} \mathrm{e} 830^{\circ} \mathrm{C}$, com pressões estimadas entre $6 \mathrm{e}$ $7 \mathrm{kbar}$, em facies anfibolito, zona da sillimanita, é concomitante à foliação $\mathrm{S}_{1}$, do tipo xistosidade, nos anfibolitos e se correlaciona ao episódio deformacional $\mathrm{D}_{\mathrm{n}-1} / \mathrm{D}$, a uma profundidade de soterramento de $22 \mathrm{~km}$. A formação das paragêneses em $M_{2}$, ocorridas sob condições de temperatura entre $450^{\circ}$ a $550^{\circ} \mathrm{C}$, de 2 a $4 \mathrm{kbar}$, ocorrido provavelmente a $7 \mathrm{~km}$ de profundidade, e os fraturamentos se correlacionam, ao episódio deformacional transtensivo/transpressivo $D_{n+1} / D_{n+3}$ (Hackspacher et al. 1996), sendo os episódios metamórficos sincrônicos a estes eventos colisionais.

Os resultados geotermobarométricos determinados neste trabalho são elevados para o o intervalo admitido para a facies anfibolito. Alguns autores consideram que estes valores são indicativos de facies granulito ou, pelo menos, uma zona de transição anfibolito-granulito. Contudo, como na região não se encontrou assembléia mineral com ortopiroxênio, o que indicaria a facies granulito, julga-se que o intervalo de temperatura da facies anfibolito e, por conseqüência, das paragêneses desenvolvidas, possa ser mais expandido.

As condições de metamorfismo do Complexo Itapira obtidas pelas análises dos anfibolitos de Ermida podem ser estendidas das folhas Jundiaí e Indaiatuba para a região abrangida pelas 
Tabela 3 - Continuação

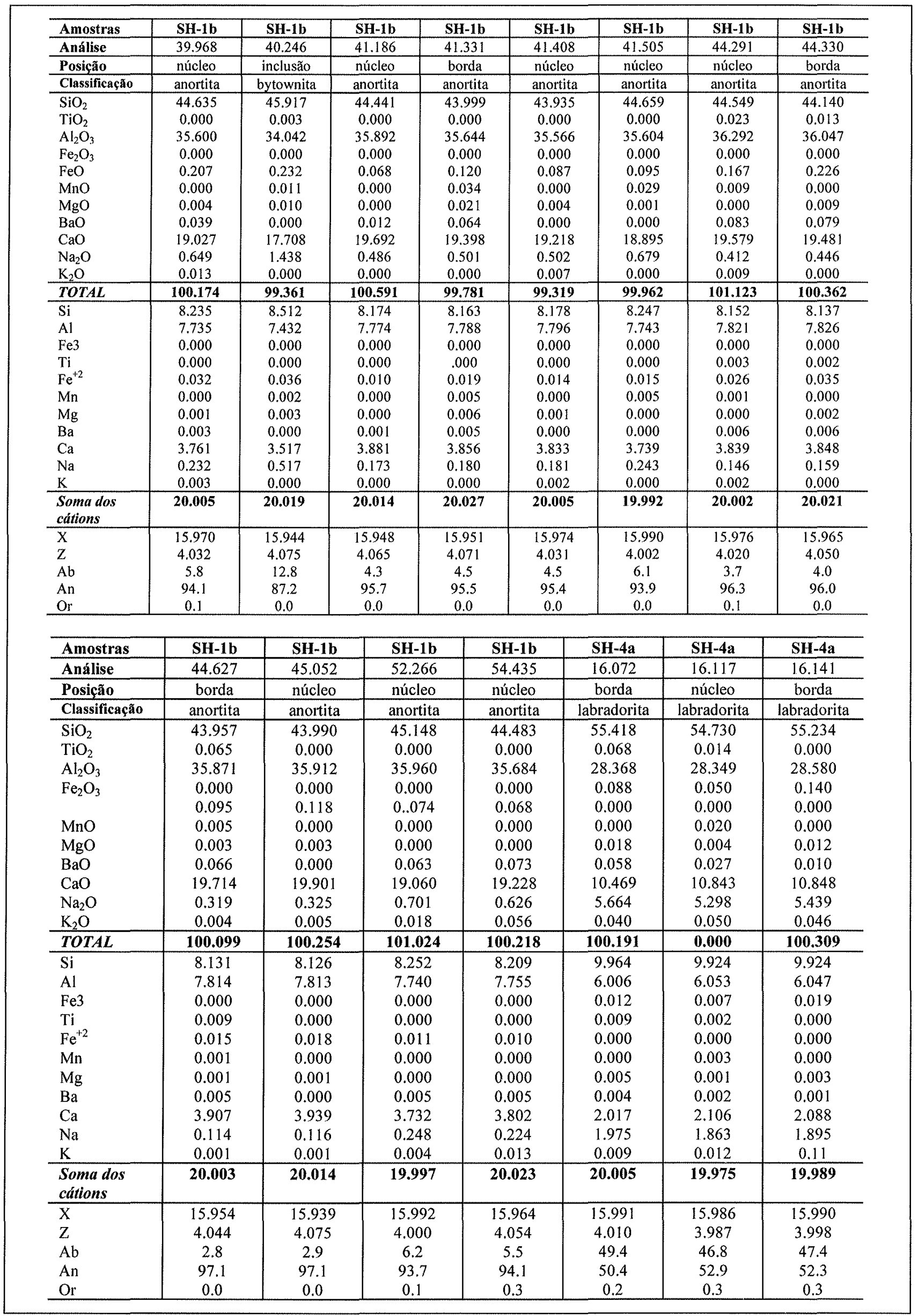


folhas Cabreúva e Atibaia (SP) devido às similaridades dos resultados entre estas e provavelmete tenham sido alcançadas em todo o Complexo Itapira.
Agradecimentos À FAPESP e ao CNPq pelo financiamento da pesquisa. A Everton Gabriel do Nascimento pela correção do abstract. Ao revisor da RBG pelas sugestões.

Tabela 4 :Composição química e fórmula estrutural de clinopiroxênio.

\begin{tabular}{|c|c|c|c|}
\hline Amostra & SH-1a & SH-1a & SH-1b \\
\hline análise & 39.717 & 41.254 & 53.752 \\
\hline posição & núcleo & borda & borda \\
\hline $\mathrm{SiO}_{2}$ & 51.783 & 51.642 & 52.935 \\
\hline $\mathrm{TiO}_{2}$ & 0.192 & 0.093 & 0.034 \\
\hline $\mathrm{Al}_{2} \mathrm{O}_{3}$ & 1.689 & 0.927 & 3.029 \\
\hline $\mathrm{FeO}$ & 10.225 & 11.075 & 13.555 \\
\hline $\mathrm{Cr}_{2} \mathrm{O}_{3}$ & 0.045 & 0.054 & 0.003 \\
\hline $\mathrm{MnO}$ & 0.186 & 0.250 & 0.309 \\
\hline $\mathrm{MgO}$ & 12.434 & 12.108 & 14.585 \\
\hline $\mathrm{CaO}$ & 23.400 & 23.596 & 12.911 \\
\hline $\mathrm{Na}_{2} \mathrm{O}$ & 0.215 & 0.163 & 0.153 \\
\hline $\mathrm{K}_{2} \mathrm{O}$ & 0.00 & 0.006 & 0.058 \\
\hline Total & 100.169 & 99.914 & 97.572 \\
\hline TSi & 1.942 & 1.949 & 2.035 \\
\hline TAl & 0.058 & 0.041 & 0.000 \\
\hline $\mathrm{TFe}^{+3}$ & 0.000 & 0.000 & 0.000 \\
\hline $\mathrm{M} 1 \mathrm{Al}$ & 0.016 & 0.000 & 0.137 \\
\hline MITi & 0.005 & 0.003 & 0.001 \\
\hline $\mathrm{M} 1 \mathrm{Fe}^{+3}$ & 0.000 & 0.000 & 0.000 \\
\hline $\mathrm{M} 1 \mathrm{Fe}^{+2}$ & 0.282 & 0.314 & 0.026 \\
\hline $\mathrm{M} 1 \mathrm{Cr}$ & 0.001 & 0.002 & 0.000 \\
\hline $\mathrm{M} 1 \mathrm{Mg}$ & 0.695 & 0.681 & 0.836 \\
\hline $\mathrm{M} 1 \mathrm{Ni}$ & 0.000 & 0.000 & 0.000 \\
\hline $\mathrm{M} 2 \mathrm{Mg}$ & 0.000 & 0.000 & 0.000 \\
\hline $\mathrm{M} 2 \mathrm{Fe}^{+2}$ & 0.038 & 0.035 & 0.410 \\
\hline $\mathrm{M} 2 \mathrm{Mn}$ & 0.006 & 0.008 & 0.010 \\
\hline $\mathrm{M} 2 \mathrm{Ca}$ & 0.940 & 0.954 & 0.532 \\
\hline $\mathrm{M} 2 \mathrm{Na}$ & 0.016 & 0.012 & 0.011 \\
\hline $\mathrm{M} 2 \mathrm{~K}$ & 0.000 & 0.000 & 0.003 \\
\hline Total de cátions & 4.000 & 4.000 & 3.997 \\
\hline $\mathrm{Ca}$ & 47.923 & 47.876 & 29,324 \\
\hline $\mathrm{Mg}$ & 35.431 & 34.183 & 46.091 \\
\hline $\mathrm{Fe}^{+2}-\mathrm{Mn}$ & 16.646 & 17.941 & 24.858 \\
\hline $\mathrm{JD} 1^{-}$ & 0.793 & 0.000 & 0.784 \\
\hline $\mathrm{AE} 1$ & 0.000 & 0.612 & 0.000 \\
\hline CFTS1 & 0.068 & 0.000 & 0.005 \\
\hline CTTS1 & 0.275 & 0.132 & 0.000 \\
\hline CATS1 & 0.024 & 0.000 & 0.000 \\
\hline WO1 & 47.320 & 47.643 & 29.251 \\
\hline EN1 & 35.256 & 34.110 & 45.985 \\
\hline FS 1 & 16.264 & 17.503 & 23.975 \\
\hline$Q$ & 1.956 & 1.985 & 1.803 \\
\hline $\mathrm{J}$ & 0.031 & 0.024 & 0.023 \\
\hline WO & 47.923 & 47.876 & 29.324 \\
\hline $\mathrm{EN}$ & 35.431 & 34.183 & 46.091 \\
\hline FS & 16.646 & 17.941 & 24.585 \\
\hline WEF & 98.431 & 98.817 & 98.758 \\
\hline $\mathrm{JD}$ & 1.569 & 0.000 & 1.242 \\
\hline $\mathrm{AE}$ & 0.000 & 0.012 & 0.000 \\
\hline
\end{tabular}


Tabela 5 - Composição química de granada obtida por microssonda eletrônica e fórmula estrutural calculada com base em 24 oxigênios.

\begin{tabular}{|c|c|c|c|c|}
\hline Amostra & SH-1a & SH-1a & SH-1b & SH-1b \\
\hline análise & 01 & 02 & 01 & 02 \\
\hline posição & intermediário & borda & borda & borda \\
\hline $\mathrm{SiO}_{2}$ & 37.928 & 38.123 & 38.658 & 38.769 \\
\hline $\mathrm{TiO}_{2}$ & 0.017 & 0.003 & 0.007 & 0.065 \\
\hline $\mathrm{Al}_{2} \mathrm{O}_{3}$ & 21.858 & 21.207 & 21.377 & 21.575 \\
\hline $\mathrm{FeO}$ & 26.164 & 27.026 & 25.419 & 23.454 \\
\hline $\mathrm{MnO}$ & 2.393 & 2.777 & 3.498 & 2.237 \\
\hline $\mathrm{MgO}$ & 3.028 & 2.794 & 3.778 & 3.762 \\
\hline $\mathrm{CaO}$ & 9.114 & 8.049 & 8.087 & 10.185 \\
\hline $\mathrm{Na}_{2} \mathrm{O}$ & 0.000 & 0.000 & 0.024 & 0.000 \\
\hline Total & 100.502 & 99.979 & 100.848 & 100.047 \\
\hline TSi & 5.957 & 6.049 & 6.040 & 6.066 \\
\hline TAl & 0.043 & 0.000 & 0.000 & 0.000 \\
\hline Total & 6.000 & 6.049 & 6.040 & 6.066 \\
\hline $\mathrm{Al}^{\mathrm{VI}}$ & 4.000 & 3.963 & 3.933 & 3.976 \\
\hline $\mathrm{Fe}^{+3}$ & 0.000 & 0.000 & 0.000 & 0.000 \\
\hline $\mathrm{Ti}$ & 0.002 & 0.000 & 0.001 & 0.008 \\
\hline $\mathrm{Cr}$ & 0.000 & 0.000 & 0.000 & 0.000 \\
\hline Total & 4.002 & 3.963 & 3.934 & 3.983 \\
\hline$\overline{\mathrm{Fe}^{+2}}$ & 3.437 & 3.586 & 3.321 & 3.069 \\
\hline $\mathrm{Mg}$ & 0.709 & 0.661 & 0.880 & 0.878 \\
\hline $\mathrm{Mn}$ & 0.318 & 0.373 & 0.463 & 0.296 \\
\hline $\mathrm{Ca}$ & 1.534 & 1.368 & 1.354 & 1.707 \\
\hline $\mathrm{Na}$ & 0.000 & 0.000 & 0.007 & 0.000 \\
\hline Total & 5.998 & 5.988 & 6.025 & 5.951 \\
\hline Total dos cátions & 16.000 & 16.000 & 16.000 & 16.000 \\
\hline Almandina & 57.300 & 59.883 & 55.124 & 51.576 \\
\hline Andradita & 0.000 & 0.000 & 0.000 & 0.000 \\
\hline Grossulária & 25.572 & 22.849 & 22.468 & 28.694 \\
\hline Piropo & 11.821 & 11.036 & 14.605 & 14.747 \\
\hline Espessartita & 5.308 & 6.232 & 7.683 & 4.982 \\
\hline Uvarovita & 0.000 & 0.000 & 0.000 & 0.000 \\
\hline XCagnt & 0.256 & 0.228 & 0.225 & 0.287 \\
\hline XFegnt & 0.573 & 0.599 & 0.552 & 0.516 \\
\hline XMggnt & 0.118 & 0.110 & 0.146 & 0.148 \\
\hline Fe_Mggnt & 4.848 & 5.425 & 3.774 & 3.495 \\
\hline
\end{tabular}

Tabela 6: Pressões obtidas, utilizando pares granada-plagioclásio-anfibólio da amostra SH-1b, segundo métodos de Kohn \& Spear (1989, 1990).

\begin{tabular}{|cccc|}
\hline & & & \\
\hline Amostras e pares & $\begin{array}{c}\text { P(kbar) obtida } \\
\text { (KOHN \& SPEAR 1989) }\end{array}$ & $\begin{array}{c}\text { P (kbar) obtida } \\
\text { (KOHN \& SPEAR 1990) }\end{array}$ & T( $\left.{ }^{\circ} \mathbf{C}\right)$ inferida \\
\hline SH-1b & 7.47 & 6.20 & 500 \\
$44.219-44.413-44.291$ & 7.28 & 6.20 & 600 \\
& 7.09 & 6.20 & 700 \\
& 6.91 & 6.20 & 800 \\
\hline
\end{tabular}


Tabela 7: Temperaturas obtidas, segundo método de Blundy \& Holland (1990), utilizando os pares anfibólio-plagioclásio das ocorrências anfiboliticas de Ermida.

\begin{tabular}{|c|c|c|}
\hline amostras e pares & P(kbar) estimada & $\mathrm{T}\left({ }^{\circ} \mathrm{C}\right)$ obtida \\
\hline & 5 & 771.83 \\
\hline SH-1a & 6 & 745.37 \\
\hline \multirow[t]{2}{*}{$50.826-51.024$} & 7 & 736.91 \\
\hline & 8 & 719.45 \\
\hline \multirow{4}{*}{ 50.883-51.024 } & 5 & 737.93 \\
\hline & 6 & 721.04 \\
\hline & 7 & 704.15 \\
\hline & 8 & 687.25 \\
\hline \multirow{4}{*}{ 49.316-49.302 } & 5 & 808.17 \\
\hline & 6 & 789.90 \\
\hline & 7 & 771.63 \\
\hline & 8 & 753.36 \\
\hline \multirow{4}{*}{ 49.339-49.302 } & 5 & 785.74 \\
\hline & 6 & 767.84 \\
\hline & 7 & 749.94 \\
\hline & 8 & 732.04 \\
\hline \multirow{4}{*}{$40.669-41.091$} & 5 & 820.05 \\
\hline & 6 & 803.11 \\
\hline & 7 & 786.17 \\
\hline & 8 & 769.23 \\
\hline \multirow{4}{*}{$38.642-39.139$} & 5 & 742.02 \\
\hline & 6 & 725.50 \\
\hline & 7 & 708.98 \\
\hline & 8 & 692.46 \\
\hline & 5 & 814.10 \\
\hline SH-4a & 6 & 798.47 \\
\hline \multirow[t]{2}{*}{$16.138-16.072$} & 7 & 782.85 \\
\hline & 8 & 767.23 \\
\hline \multirow{4}{*}{$16.226-16.141$} & 5 & 845.32 \\
\hline & 6 & 829.07 \\
\hline & 7 & 812.83 \\
\hline & 8 & 769.59 \\
\hline \multirow{4}{*}{$16.243-16.117$} & 5 & 842.73 \\
\hline & 6 & 826.46 \\
\hline & 7 & 810.19 \\
\hline & 8 & 793.92 \\
\hline
\end{tabular}




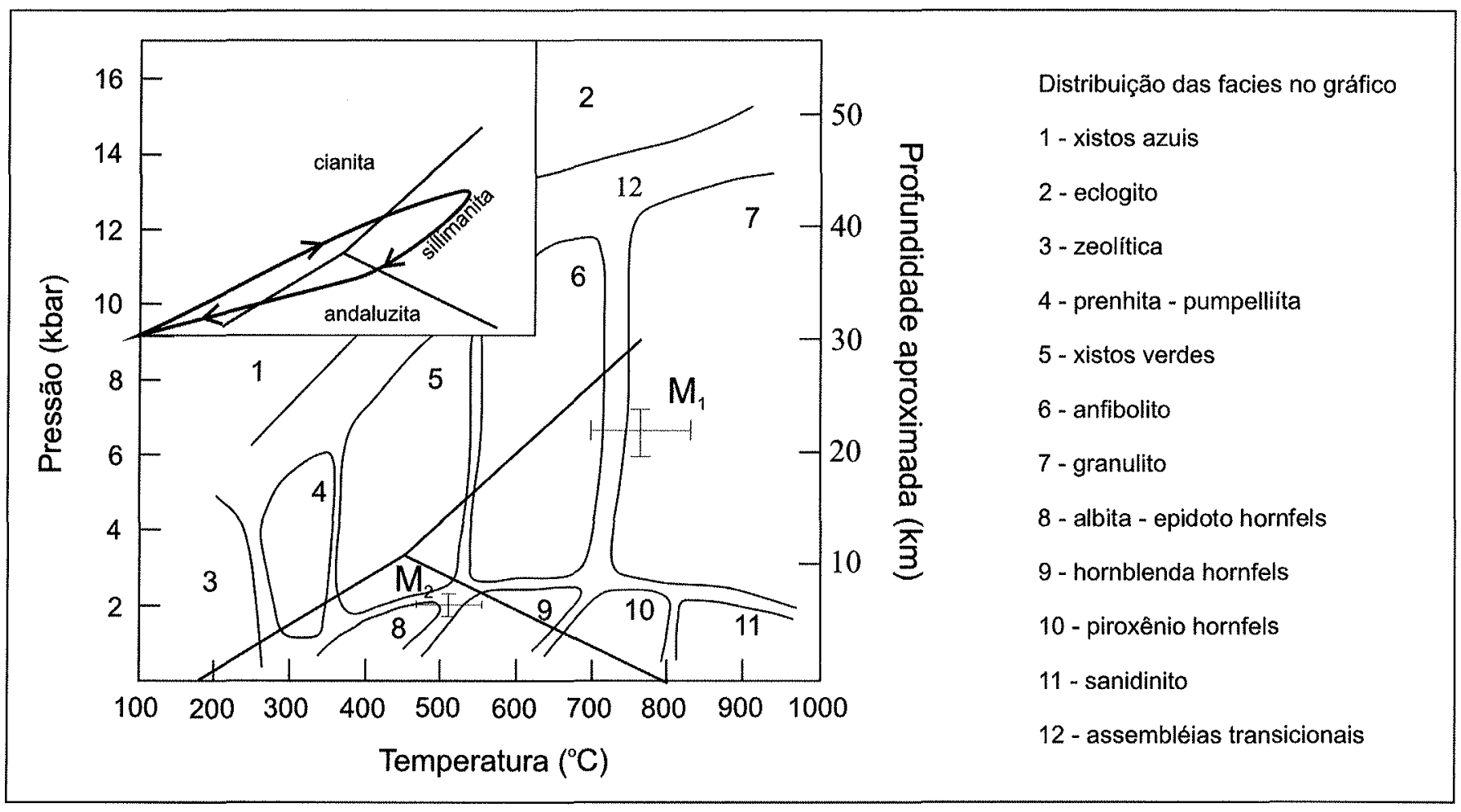

Figura 7 - Diagrama pressão - temperatura - profundidade, indicando os intervalos das condições metamórficas quantificadas e o caminhamento P-T, para as ocorrências anfiboliticas de Ermida. As divisões dos campos são segundo Yardley (1993).

\section{Referências}

Atzori P., Caculi S., Guidice A. Lo. 1984. Le anfiboliti di Monte Antenamare Catena Peloritana, Sicilia). Min. et Petrog. Acta, 38: 1 $-32$.

Bingen B., DeMaiffe D., Delhal J. 1984. Petrologic investigation in the Kasai gabro noritic complex and associated metadolerites dikes (Zaire). Am. Min., 107: 665 - 682.

Blundy J. D. \& Holland T. J. B. 1990. Calcic amphibole equilibria and a new amphibole-plagioclase geothermomether. Contr. Mineral. Petrol., 104(2): 208 - 224.

Broekamans M. A. T. M., Nijland T. G., Jansen B. H. 1994. Are stable isotopic trends in amphibolite to granulite facies transitions metamorphic or diagenetic? - an answer for the Arendal area (Bamble sector, southeastern Norway) from Mid-Proterozoic carbon-bearing rocks. Am. Jour Sci., 294: 1135 - 1165.

Cordani U. G. \& Bittencourt I. 1967. Determinações de idade potássioargônio em rochas do Grupo Açungui. In: XXI Congr. Bras. Geol., Curitiba, 218-233.

Ebert H. 1971. Os paraibides entre São João Del Rei (MG) e Itapira (SP) e a bifurcação entre Paraibides e Araxaides. Bol. esp. n.1, $\mathrm{SBG} / \mathrm{SP}$.

Ebert H. D., Artur A.C., Chemale Jr. F., Batista M., Van Schmus W. R. 1994. Regimes tectônicos e idades U/Pb em zircão do Complexo Socorro no contexto da faixa Ribeira: um exemplo de magmatismo transpressivo. In: XXXVIII Congr. Bras. Geol., Bal. Camboriú, SC, bol. res. exp., 1: $260-261$.

Frimmel H. E. \& Hartnardy C. J. H. 1992. Blue amphiboles and their significance for the history of the Pan-African Gariep Belt, Namibia. J. Met. Geol., 10(5): 651 - 670.
Ghent E. D., Nichols J., Stout M. Z., Rottenfusser B. 1977. Clinopyroxene amphibolites boudins from Three Valley Gap, Brittish Columbia. Can. Min., 15: 269-282.

Green T. H. \& Adam D. H. 1991. Assessment of the garnet-clinopyroxene $\mathrm{Fe}-\mathrm{Mg}$ exchange thermometer using new experimental data. J. Met. Geol., 9: 341-347.

Guidotti C. V. 1970. The mineralogy and petrology of the transition from lower to upper sillimanite zone in the Oquossoc Area, Maine. J. Petrol., 11(2): 277 - 336.

Hackspacher P. C. 1994. Tectônica transpressiva-transtrativa e alojamento de rochas plutônicas, a exemplo da folha Cabreúva (SP) 1:50000. Tese de Livre Docência, DPM/IGCE/UNESP/Rio Claro, $203 \mathrm{p}$.

Hackspacher P. C., Dantas E. L., Spoladore A., Fetter A. 1999. Evolução da Faixa Ribeira, na região de Apiaí, sudeste do Brasil: geocronologia $\mathrm{U} / \mathrm{Pb}$ em zircão de rocha metabásicas e granito. In: VI Simp. Geol. Sudeste, São Pedro (SP): p.12.

Hackspacher P. C., Godoy A. M., Oliveira M. A. F. de. 1992a. Geologia da folha Pirapora, SP em 1:25000. In: XXVII Congr. Bras. Geol., SBG/SP, São Paulo, 127-128.

Hackspacher P. C., Moraes N., Zanardo A., Godoy A. M., Oliveira M. A. F. de. 1992 b. A tectônica transcorrente/transpressiva brasiliana na folha São Roque - SP. In: XXVII Congr. Bras. Geol, SBG/SP, São Paulo, 348-349.

Hackspacher P. C., Godoy A. M., Oliveira M. A. F. de. 1996. Geologia da folha Cabreúva - SP, 1:50000. Geociências, Ed. UNESP, 15, n. esp.:111-131. 
Hackspacher P. C., Oliveira M. A. F. de, Godoy A. M. 1991. Controle do nível metamórfico e da disposição dos corpos granitóides pela tectônica Dn+3/transcorrente na folha Cabreúva. In: II Simp. Geol. Sudeste, São Paulo, 151-154.

Hackspacher P. C., Oliveira M. A. F. de, Godoy A. M. 1992c. Geologia dos grupos Serra do Itaberaba/São Roque na folha Cabreúva - SP, 1:50000. In: XXVII Congr. Bras. Geol., SBG/SP, São Paulo, 124125.

Hasui Y., Almeida F. F. M. de, Neves B. B. de B. 1978. As estruturas brasilianas. In: XXX Congr. Bras. Geol., Recife, 6: 2423 - 2435 .

Hasui Y. \& Hama M. 1972. Geocronologia do Grupo São Roque pelo método do potássio-argônio. Rev. Bras. Geoc., 2: 18 - 24.

Kohn M. J. \& Spear F. S. 1989. Empirical calibration of geobarometers for the assemblage garnet thornblende + plagioclase + quartz. Am. $\operatorname{Min} ., 74(1,2): 74-84$.

Kohn M. J. \& Spear F. S. 1990. Two geobarometers for garnet amphibolites, with applications to southeastem Vermont. Am. Min., 75: $89-96$.

Kostyuk E. A. \& Sobolev V. S. 1969. Paragenetic types of calciferous amphiboles of metamorphic rocks. Lithos, 2: $67-82$.

Kretz R. 1983. Symbols for rock-forming minerals. Am. Min., 68: 277 -279 .

Leake B. E. 1978. Nomenclature of amphiboles Can. Min., 16: 501 -520 .

Leake B. E., Woollwy A.R., Arps C. E. S., Birch W. D., Gilbert M. C., Grice J. D., Hawthorne F. C., Kato A., Kisch H. J., Krivovichev V. G., Linthout K., Laird J., Mandarino J., Maresch W. V., Nickel H. E., Rock N. M. S., Schumacher I. C., Smith D. C., Stephenson, N. C. N., Ungaretti L., Whitaker E. J. W., Youzhi G. 1997. Nomenclature of amphiboles report of the subcommittee on amphiboles of the International Mineralogical Association Commission on New Minerals Names. Eur. J. Mineral., 9: 623 - 651.

Leite P. R. B. \& Lima E. S. 1991. Caracterização química de biotita, granada e plagioclásio em metapelitos da facies anfibolito alta a granulito (Santa Maria da Boa Vista, PE). In: III Congr. Bras. Geoquim., 2: $695-697$.

Liou J. G., Kunyioshi S., Ito K. 1974. Experimental studies of the phase relations between greenschist and amphibolite in a basaltic system. Am. J. Sci., 274: 613-632.

Lourenço J. C. R., Lazzarini A. P., Zanardo A. 1999. Rochas metaultramáficas da Faixa Itapira/Amparo. In: VI Simp. Geol. Sudeste, São Pedro (SP), p.25.

Neves M. A. 1999. Evolução Cenozóica da Região de Jundiai (SP). Dissertação de Mestrado, IGCE/UNESP, Rio Claro, 135p.

Neves M. A., Morales N., Borges M. S., Ebert H. D. 2003. Compartimentação tectônica da região de Jundiaí (SP). Rev. Bras. Geoc., 33(2): 167-176.

Nogueira D. O., Correia P. R., Alves R. 1985. Projeto Jundiaí, grupo V. SICCT/PRÓ-MINÉRIO/IGCE/UNESP, Rio Claro, 108p.

Morimoto N. 1988. Nomenclature of pyroxenes. Min. Mag., 52: 535
$-550$.

Oliveira M. A. F. de, Batista J. J., Morales N. 1987. Caracterização geoquímica de rochas anfibolíticas do Grupo Itapira nas folhas Atibaia e Jundiaí (SP). In: VI Simp. Reg. Geol., SBG/SP, 1: 23-32.

Richard L. 1995. MINPET, Mineralogical and petrological data prossessing system, v. 2.02 .

Rollinson H. 1981. Garnet-pyroxene thermometry and barometry in the Scourie granulites, NW Scotland, Lithos, 14: 224-238.

Schumacher J. C. 1991. Empirical ferric iron correction; necessity, assumptions, and effects on select geothermobarometers. Min. Mag., 55: 3-18.

Soto J. I. \& Soto V. M. 1993. Program for thermobarometry and activity calculations with mafic and ultramafic assemblages, v. 2.0 - Dep. Geodinâmica, Granada University, Spain.

Souza S. C. A. de. 1997. Anfibolitos ortoderivados do Complexo Itapira e Bloco São Roque nas folhas: Cabreúva, Sorocaba, Itu e São Roque (SP). Petrografia, litoquímica, quimica mineral e termobarometria. - Dissertação de. Mestrado, IGCE/UNESP, Rio Claro, $137 \mathrm{p}$.

Souza S. C. A. de. 2001. Petrologia dos corpos anfiboliticos de Ermida, Aluminio e Pirapora do Bom Jesus (SP). Tese de Doutorado, IGCE/UNESP, Rio Claro, $178 \mathrm{p}$. e anexos.

Souza S. C. A. de \& Oliveira M. A. F. de. 1998. Petrografia do corpo anfibolítico de Ermida (SP). In: XL Congr. Bras. Geol., Belo Horizonte (MG), p.487.

Souza S. C. A. de, Oliveira M. A. F. de, Zanardo A. 1996. Petrologia e litoquímica dos anfibolitos do Complexo Itapira: folhas Águas de Lindóia (SP/MG) e Cabreúva (SP). In: XXXIX Congr. Bras. Geol., Salvador (BA), 131-133.

Souza S. C. A. de, Silva V. R. da. 1992. Geologia da Área - I-Região a norte da cidade de Atibaia e dados de tipologia de zircão do Complexo Socorro. Trabalho de Graduação, DPM/IGCE/UNESP, Rio Claro, 180p.

Spear F. S. 1981. An experimental study of homblende stability and compositional variability in amphibolite. Am. J. Sci., 281(6): 697 734.

Tassinari C. C. G., Kawashita K., Van Schmus W. R., Taylor P. N. 1988 As idades das rochas e dos eventos metamórficos da região sudeste do Estado de São Paulo. In: XXXV Congr. Bras. Geol., Belém (PA), 6: 2840-2848.

Wernick E. 1978. Contribuição à estratigrafia do Pré-Cambriano do leste do Estado de São Paulo e áreas vizinhas. Rev. Bras. Geoc., 8(3): 206-216.

Wernick E., Weber-Diefenbah K., Correia P. R. 1987. O granitóide Nazaré Paulista: dados petrográficos, químicos e de tipologia de zircão. In: IV Simp. Geol. Sudeste, SBG/SP, 1: 123-134.

Yardley B. W. 1993. An introduction to metamorphic petrology - Longman Earth Sci., $4^{\mathrm{a}}$ ed., 248p.

Manuscrito A-1609 Revisão aceita em 14 de junho de 2006 
Termobarometria das ocorrências anfiboliticas de Ermida, complexo Itapira (SP) 